\title{
Influence of Oceanic Heat Transport Upon the Sensitivity of a Model Climate
}

\author{
M. J. Spelman and S. Manabe
}

Geophysical Fluid Dynamics Laboratory/National Oceanic Atmospheric Administration, Princeton University

\begin{abstract}
The influence of oceanic heat transport on the sensitivity of climate to an increase of the atmospheric $\mathrm{CO}_{2}$ concentration is studied by comparing the $\mathrm{CO}_{2}$-induced changes of two mathematical models. The first model is a general circulation model of the coupled ocean-atmosphere system which includes ocean currents. In the second model the oceanic component of the first model is replaced by a simple mixed layer without ocean currents. Both models have limited computational domain with idealized geography and annual mean insolation. For each model, the sensitivity of climate is evaluated from the difference between the equilibrium climates of the normal $\mathrm{CO}_{2}$ and 4 times the normal $\mathrm{CO}_{2}$ concentrations. The results indicate that the presence of ocean currents reduces the sensitivity of surface air temperature because of the difference in magnitude of the surface albedo feedback effect. The poleward transport of heat by ocean currents raises the surface temperature at high latitudes, shifts poleward the margins of snow and sea ice, decreases the contribution of the albedo feedback effect, and reduces the sensitivity of climate. The equilibrium response of climate is compared with the transient response of climate to a sudden increase of atmospheric $\mathrm{CO}_{2}$ content. According to this comparison, the latitudinal dependence of the equilibrium response of zonally averaged surface temperature is qualitatively similar to the transient response approximately 25 years after the time of the sudden $\mathrm{CO}_{2}$ increase. This result suggests that the distribution of the zonally averaged temperature change in response to a gradual increase of atmospheric carbon dioxide also resembles the distribution of the equilibrium response provided that the characteristic time scale of the $\mathrm{CO}_{2}$ increase is longer than 25 years.
\end{abstract}

\section{INTRODUCTION}

Several studies have been made of the climatic effect of increasing the atmospheric $\mathrm{CO}_{2}$ concentration in general circulation models of the atmosphere [e.g., Manabe and Wetherald, 1975, 1980]. However, none of these studies takes into consideration the effect of oceanic heat transport, with the exception of the recent study by Bryan et al. [1982] which investigates the transient response of climate to a sudden increase of $\mathrm{CO}_{2}$ in a coupled ocean-atmosphere model. The present study is an outgrowth of their study. We investigate the influence of oceanic heat transport upon the equilibrium response of climate to an increase in the atmospheric $\mathrm{CO}_{2}$ concentration.

Very little is known about the effects of ocean currents upon the sensitivity of the climate. Held and Suarez [1974] speculated that the poleward transport of heat by ocean currents reduces the meridional temperature gradient, increases the latitudinal shift of the margin of snow-covered area responding to a given change in surface temperature, and thus enhances climate sensitivity by increasing the contribution of the albedo feedback process. Their argument applies to the comparison of two climates with the same amount of ice but with different meridional temperature gradients. However, we also expect oceanic heat transport to shift the margins of snow cover and sea ice poleward. In one-dimensional energy balance models of the atmosphere [e.g., Budyko, 1969], the equilibrium response of surface temperature to a given change in the solar constant typically decreases as the ice margin retreats toward the poles. If this effect dominates, oceanic heat transport should reduce the sensitivity of climate.

In view of these counteracting influences of oceanic heat transport, we decided to investigate whether ocean currents enhance or reduce the sensitivity of climate. For this purpose,

This paper is not subject to U.S. Copyright. Published in 1984 by the American Geophysical Union.

Paper number 3C1287. two climate models are constructed. The first is a coupled ocean-atmosphere model with ocean currents; the second is a mixed layer ocean-atmosphere model without ocean currents. The responses of these two model climates to an increase of the atmospheric $\mathrm{CO}_{2}$ concentration are compared in order to determine the influence of oceanic heat transport upon the climate sensitivity. The main emphasis in this comparison is on the thermal response of the model climate to increasing atmospheric $\mathrm{CO}_{2}$. Previous studies have shown that the $\mathrm{CO}_{2}$-induced temperature change has significant variation with respect to latitude. This study investigates how the latitudinal distribution of the response is altered by the influence of ocean currents.

Both of the models used in this study have the same limited computational domain with idealized geography and annual average insolation. With these simplifications, the numerical experiments were completed in a reasonable amount of computer time. Despite the simplifications, this preliminary study yields some insights into the effects of oceanic heat transport upon the sensitivity of climate.

Relevant aspects of the climate models are described in section 2, and in section 3 the plan of the numerical experiments is presented. A comparison of the model climates with and without the effects of ocean currents is given in section 4 for the normal concentration of atmospheric $\mathrm{CO}_{2}$. Section 5 contains an assessment of the effects of oceanic heat transport on climate sensitivity. A comparison of the sensitivity obtained in this study with the sensitivities obtained in previous studies is presented in section 6 . In section 7 the sensitivity of the transient response of climate, as reported in a companion paper by Bryan et al. [1982], is compared with the sensitivity of the equilibrium climate response from the present study.

\section{Numerical Models}

As explained in section 1, two numerical models are used in this study. This section contains descriptions of both the coupled ocean-atmosphere model (with ocean currents) and the 


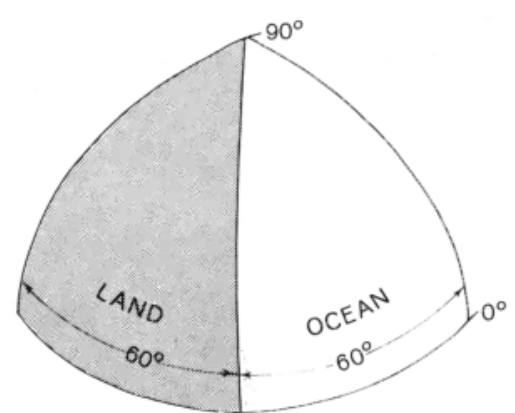

Fig. 1. Computational domain for both the ocean-atmosphere model and the mixed layer ocean-atmosphere model.

mixed layer ocean-atmosphere model (without ocean currents). The computational domain and geometry for both models is shown in Figure 1. The domain, which is one sixth of the globe, is divided into two equal areas of continent and ocean extending from equator to pole. Cyclic continuity is specified in the atmosphere at the meridional boundaries, which are $120^{\circ}$ of longitude apart. A condition of mirror symmetry is imposed at the equator.

\subsection{Ocean-Atmosphere Model}

The atmospheric component of the coupled oceanatmosphere system is very similar to the general circulation model of the atmosphere described by Wetherald and Manabe [1981]. The spectral method of numerical integration is used in the model to predict tendencies of horizontal divergence, vertical component of vorticity, temperature, water vapor, and surface pressure, based on the equations of motion, the thermodynamical equation, the prognostic equation of water vapor, and the continuity equation of mass. Horizontal distributions of these variables are represented by a finite number of spherical harmonics. Tendencies of the prognostic variables are computed at all grid points and then transformed to the spectral domain. The horizontal resolution of the spectral representation is determined by the maximum number of spectral components retained. For this study, the maximum wave number retained is 15 in the zonal and meridional directions in the spectral truncation. Vertical derivatives are computed by the finite difference method at nine unevenly spaced levels in the atmosphere. The numerical time integration of the prognostic equations is conducted by a semi-implicit method in which the linear and nonlinear components of the rate of change of a variable are separated and are time integrated implicitly and explicitly, respectively. A time smoothing technique developed by Robert [1966] is applied at each time step to prevent the growth of fictitious computational waves. Further details of the dynamics of the spectral model are given by Gordon and Stern [1982].

The annual mean distribution of solar radiation is prescribed at the top of the atmosphere. The effects of clouds, water vapor, ozone, and carbon dioxide are included in the computation of both solar and terrestrial radiation. The mixing ratio of carbon dioxide is assumed to be constant everywhere. For ozone, a zonally uniform annually averaged distribution is specified as a function of latitude and height. Cloud cover is prescribed at zonally uniform values as a function of latitude and height. The distribution of water vapor is determined from the time integration of the prognostic equation of water vapor. The solar constant is $1356 \mathrm{~W} / \mathrm{m}^{2}$.

Surface temperatures of the continent are calculated from the boundary condition that no heat is stored in the earth's surface. That is, the contributions from net fluxes of solar and terrestrial radiation and turbulent fluxes of sensible and latent heat must balance locally. The computation of solar radiation in the heat balance requires a distribution of surface albedo. Albedo of the soil surface is specified as a function of latitude, as given by Manabe [1969]. Over snow cover, larger values of albedo are used. When the surface temperature is below $-10^{\circ} \mathrm{C}$, the albedo is $70 \%$ for snow; above $-10^{\circ} \mathrm{C}$, the snow albedo is $60 \%$.

The oceanic component of the coupled model is similar to the model described by Bryan and Lewis [1979] and Bryan et al. [1975]. Velocity, temperature, and salinity are predicted, and density is calculated from a realistic equation of state. In addition, the ocean model includes a simplified method for calculating the growth of sea ice in polar regions. (The prognostic scheme of sea ice used in this model is identical to the scheme in the mixed layer ocean-atmosphere model described below.) The computational grid in the ocean model is a latitude-longitude grid, having a resolution of $4.4^{\circ}$ latitude and $3.8^{\circ}$ longitude. Twelve levels in the vertical, as in Bryan and Lewis [1979], resolve the vertical structure of the ocean to a uniform depth of $5000 \mathrm{~m}$ and give a detailed representation of the ocean thermocline.

The box diagram in Figure 2 illustrates the major components of the coupled ocean-atmosphere model and the interaction among these components. The atmosphere and ocean of the coupled model interact with each other through exchanges of heat, water, and momentum. Components of heat exchange are the net radiative flux and turbulent fluxes of sensible and latent heat. The components of water (or ice) exchange are evaporation (or sublimation), rainfall (or snowfall), and runoff from the continents. The ocean surface temperature and sea ice predicted in the ocean are used as the lower boundary condition for the atmosphere. Details of the heat, moisture, and momentum exchange processes are given by Manabe et al. [1975].

\subsection{Mixed Layer Ocean-Atmosphere Model}

This model was constructed by replacing the oceanic component of the ocean-atmosphere model described above with a mixed layer model of the ocean. The mixed layer ocean model is identical to that used by Manabe and Stouffer [1980]. The model consists of a vertically isothermal layer of static water with a uniform depth of $68 \mathrm{~m}$. The rate of temperature change of the mixed layer ocean is computed from the requirement of heat balance, which includes the fluxes of radiation and exchanges of sensible and latent heat between ocean and atmos-

\section{ATMOSPHERE}

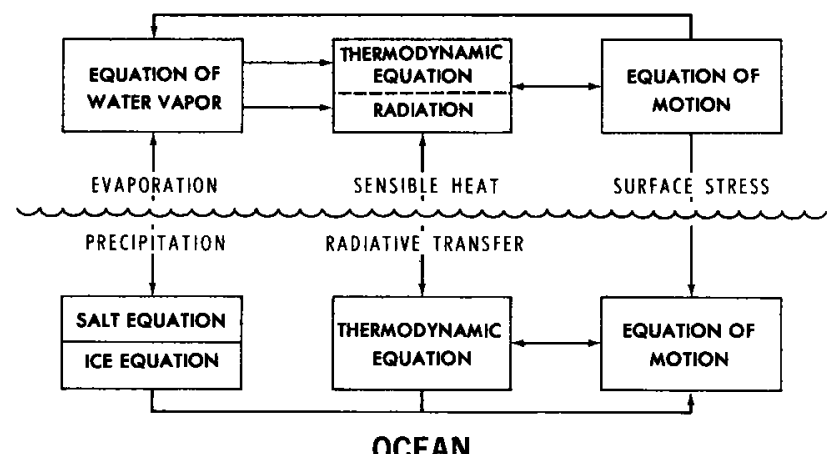

Fig. 2. Diagram of the interaction of the major components of the coupled ocean-atmosphere model. 

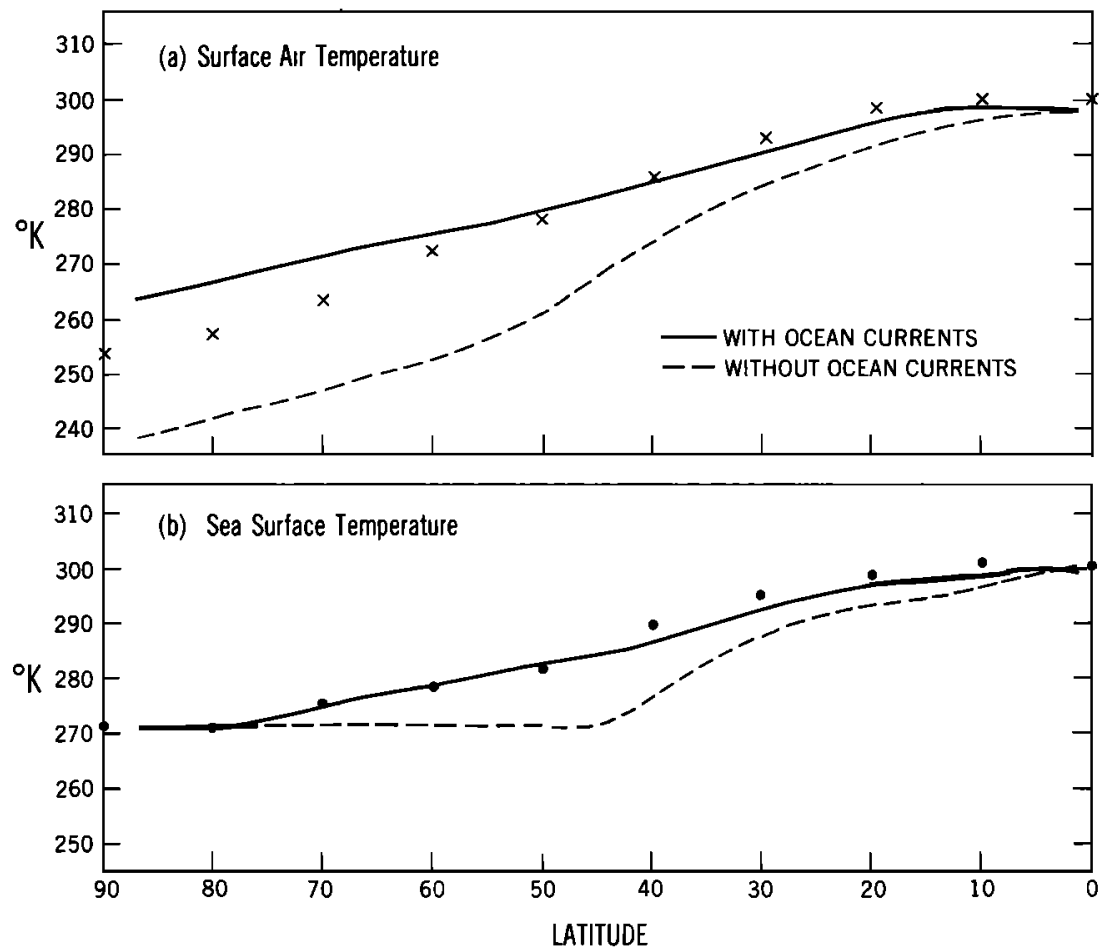

Fig. 3. Zonally averaged values of $(a)$ surface air temperature and $(b)$ sea surface temperature (degrees Kelvin) of the model with ocean currents (solid lines) and the model without ocean currents (dashed lines) as a function of latitude for the normal $\mathrm{CO}_{2}$ case. Crosses indicate observed values from Crutcher and Meserve [1970]. Dots indicate observed values from U.S. Navy Hydrographic Office [1964].

phere. When sea ice is present in the model, the temperature of the ocean beneath the ice remains at the freezing point, and the heat flux through the ice is balanced by the latent heat of freezing or melting at the bottom of the ice. This process, together with melting of the ice surface, sublimation, and snowfall, determines the change of ice thickness. The albedo of the sea ice surface is $70 \%$ when the surface temperature is below $-10^{\circ} \mathrm{C}$; above $-10^{\circ} \mathrm{C}$, the ice albedo is $60 \%$.

The mixed layer ocean model resembles the actual ocean in that it provides an unlimited source of moisture for the hydrologic cycle and has heat capacity. However, the influences of horizontal heat transport by ocean currents and heat exchange with deeper layers of the ocean are not included.

\section{NUMERICAL EXPERIMENTS}

To evaluate the effects of oceanic heat transport upon the sensitivity of climate, two sets of numerical experiments are conducted as outlined in section 1. Each set of numerical experiments consists of two long-term integrations of a model in which the normal and 4 times the normal $\mathrm{CO}_{2}$ concentrations are prescribed. The difference between the two equilibrium climates, which emerge asymptotically from these time integrations, indicates the response of each model climate to the quadrupling of the atmospheric $\mathrm{CO}_{2}$ concentration. By comparing the results from these two sets of experiments, the influence of oceanic heat transport upon the sensitivity of climate is investigated. In these experiments the increase in $\mathrm{CO}_{2}$ amount is chosen to be large compared to any probable increase in the actual atmosphere in order to discriminate the $\mathrm{CO}_{2}$-induced change from the natural fluctuations of the model climate. According to the sensitivity study by Manabe and Wetherald [1980], which used a general circulation model with a limited computational domain, the increase of atmo- spheric zonal mean temperature is almost linearly proportional to the increase of the logarithm of the $\mathrm{CO}_{2}$ amount. The results of their study suggest that the increase of atmospheric zonal mean temperature caused by a smaller increase in $\mathrm{CO}_{2}$ amount could be inferred from the results of the present study.

The numerical time integration of the ocean-atmosphere model is performed by use of a nonsynchronous method which has been used in previous studies [Manabe and Bryan, 1969; Manabe et al., 1975]. Since the ocean has a much larger thermal inertia (heat capacity) than the atmosphere, 110 years of the ocean are integrated concurrently with 1 year of the atmosphere in order to optimize the computer time required to reach climate equilibrium. In the deeper layers of the model ocean, the convergence toward equilibrium is accelerated further by artificially reducing the heat capacity of water, as described by Bryan and Lewis [1979]. Convergence to climate equilibrium for the normal $\mathrm{CO}_{2}$ experiment is obtained after integrating the model over the period of 7.8 years for the atmosphere, 850 years for the ocean. Because of the acceleration technique mentioned above, the effective period of time integration for the deeper ocean is 23,000 years. For the increased $\mathrm{CO}_{2}$ experiment, the corresponding time integration periods for the atmosphere, ocean, and deeper ocean are 11.8 years, 1290 years, and 35,000 years, respectively.

The nonsynchronous method is also used for the time integration of the mixed layer ocean-atmosphere model. Since the mixed layer ocean has a smaller thermal inertia than the full ocean, the ratio of atmospheric-to-oceanic period of integration is changed. For the normal $\mathrm{CO}_{2}$ case, the integration of the atmosphere over a period of 4.5 years is performed concurrently with 90 years integration of the ocean. This nonsynchronous integration is followed by a regular, fully synchronized, mode of integration over an additional period of 3.3 years. For the increased $\mathrm{CO}_{2}$ case, the time integration of 


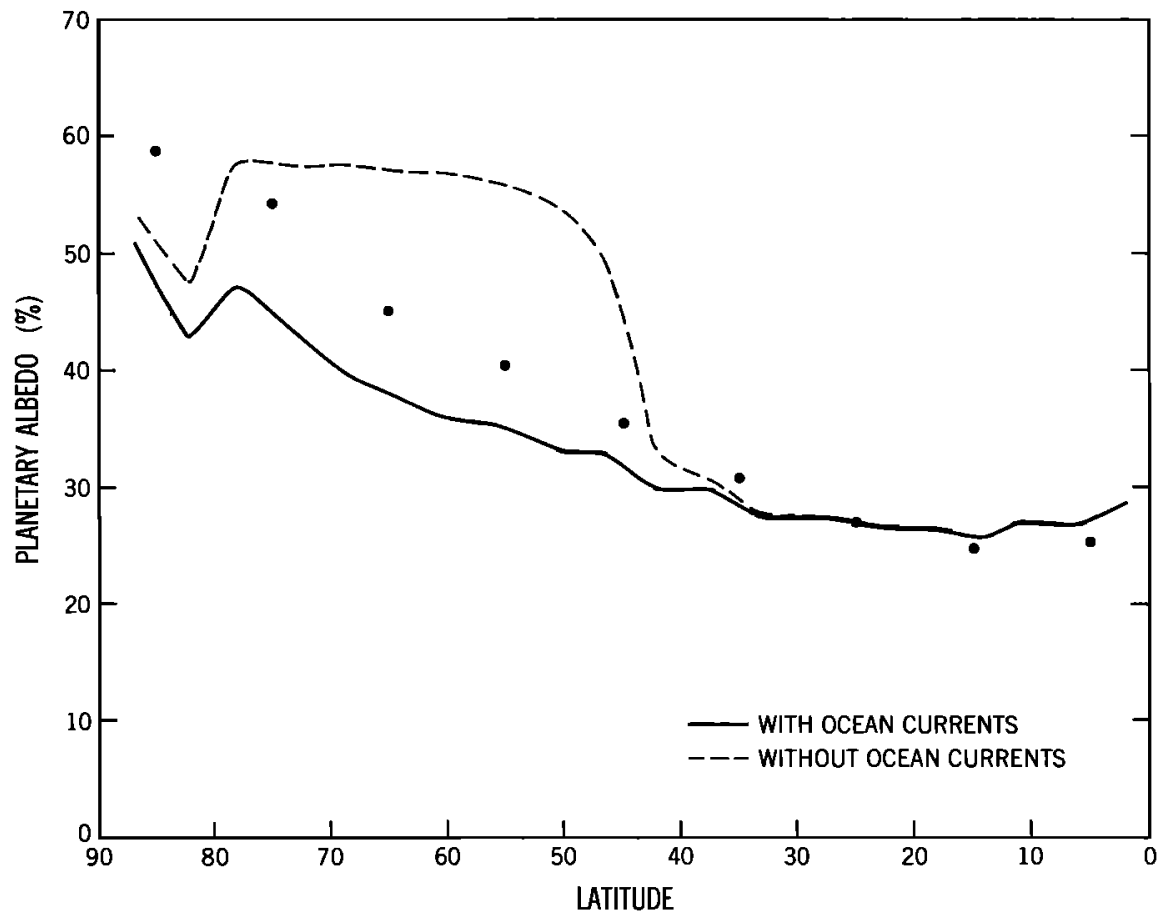

Fig. 4. Zonally averaged planetary albedo (percent) of the model with ocean currents (solid line) and the model without ocean currents (dashed line) as a function of latitude for the normal $\mathrm{CO}_{2}$ case. Dots indicate observed values from Ellis and Vonder Haar [1976].

the atmosphere over 2.8 years is performed concurrently with 55 years integration of the ocean, followed by a fully synchronized integration over 2.8 additional years. The initial data for the increased $\mathrm{CO}_{2}$ experiment is the state of the normal $\mathrm{CO}_{2}$ experiment after 2.5 years of time integration.

The results from the model experiments presented in the following sections represent the time-averaged states of the mixed layer ocean-atmosphere models over the final 600 days of integration. For the ocean-atmosphere models, the timeaveraged states are the final 600 days of the atmosphere model integration and $\mathbf{3 0 0}$ years of the ocean model integration.

\section{Simulated Climate}

In this section we describe the thermal structures of the ocean-atmosphere model (with ocean currents) and the mixed layer ocean-atmosphere model (without ocean currents) for the case of normal concentrations of $\mathrm{CO}_{2}$. The results presented here are the basis for discussing the sensitivity of the model climates in the following section. Although it is not the purpose of this paper to discuss details of the model simulation results, a discussion of some basic features of the simulated climate is necessary. This is because the reliability of the sensitivity analysis depends on the similarity between the observed and the model climates.

One of the effects of ocean currents on the climate is to transport heat poleward, which increases sea surface temperatures at high latitudes and reduces the meridional gradient of temperature. This effect is depicted in Figure $3 a$ and $3 b$, which shows zonally averaged surface air temperatures (over ocean and continent) and sea surface temperatures for the models with and without ocean currents. The surface air temperatures of the model atmosphere in Figure $3 a$ are the temperatures at the lowest finite difference level located at an altitude of about $70 \mathrm{~m}$. Sea surface temperatures in Figure $3 b$ over ice-covered regions of the model ocean remain at the freezing point of sea ice, which accounts for the constant values at high latitudes. The difference in surface air temperature between the models is very small in the tropics but increases with latitude and becomes particularly large at high latitudes. When compared with observed annual mean values, the surface air temperatures of the model with ocean currents are too high at high latitudes, whereas the sea surface temperatures are closer to observed values. On the other hand, surface air temperatures and sea surface temperatures of the mixed layer oceanatmosphere model are lower than observed.

An important consequence of the poleward heat transport by the oceans is the poleward retreat of snow and sea ice cover due to warming at high latitudes. A significant reduction in the planetary albedo can be expected as a result. (Here, planetary albedo is defined as the percentage of reflected solar radiation to the incoming solar radiation at the top of the atmosphere.) This is evident in Figure 4, which indicates the large difference of planetary albedo at high latitudes between the models with and without ocean currents. In general, the planetary albedo of the model with ocean currents is significantly smaller than the observed values poleward of $50^{\circ}$ latitude. On the other hand, the planetary albedo of the model without ocean currents is much larger than the observed values at high latitudes because of the excessive coverage of snow and sea ice.

An analysis of the heat balance at the earth's surface yields further insight into the influence of ocean circulation on the temperature at high latitudes of the model. The heat balance components at the earth's surface are the fluxes of sensible heat, latent heat, and net radiation. The net radiation flux represents the difference between net downward solar radiation and net upward longwave radiation. In addition, over the sea surface the heat flux from the interior to the surface of the ocean contributes to the surface heat balance. Zonally averaged values of the heat balance components at each lati- 

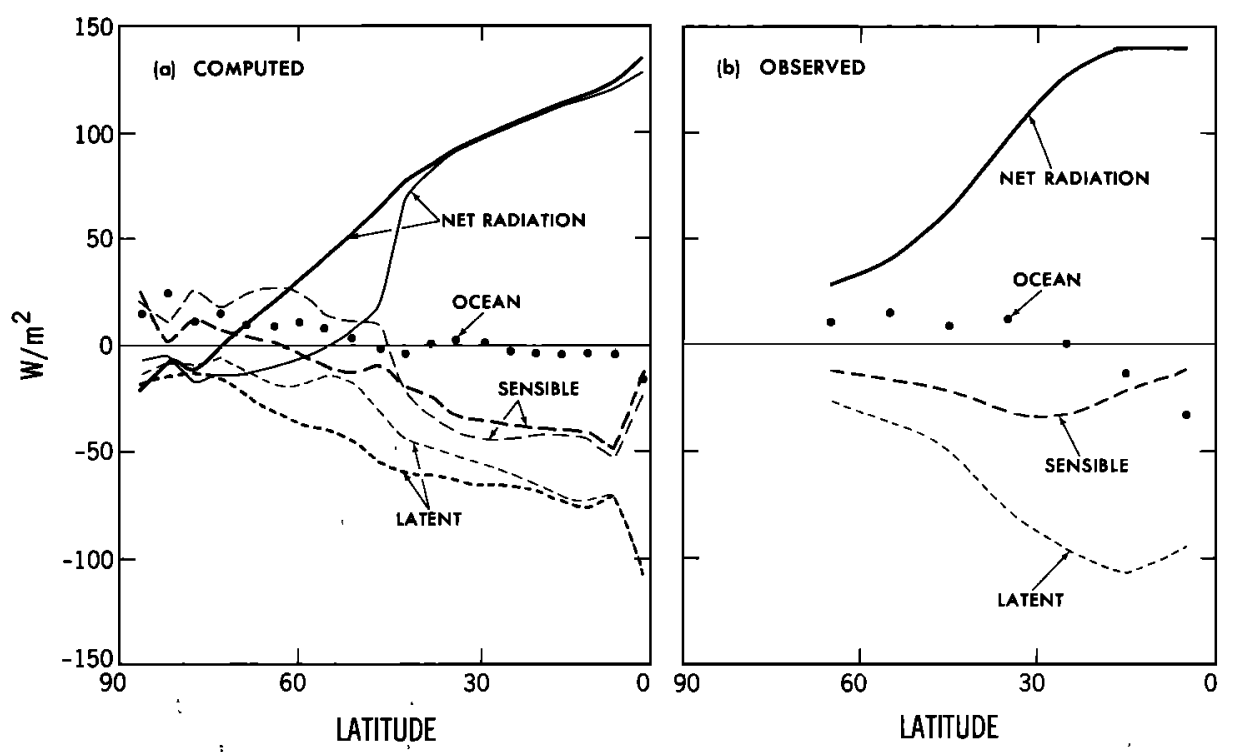

Fig. 5. Zonally averaged components of the heat balance at the earth's surface $\left(\mathrm{W} / \mathrm{m}^{2}\right)$ as a function of latitude, (a) computed by the model with ocean currents (heavy lines) and by the model without ocean currents (light lines) for the normal $\mathrm{CO}_{2}$ case, (b) observed estimatés from Budyko [1974].

tude are shown in Figure $5 a$ for the models with and without ocean currents. This figure shows the relatiye importance of the processes responsible for the surface temperature change induced by the ocean currents. In the region poleward of $45^{\circ}$ latitude, the surface gains heat from the interior of the acean as a result of poleward transport of heat by the ocean. Also, the net radiation flux at high latitudes is larger in the model with ocean currents and has largest increases in the region of largest decreases of planetary albedo in Figure 4. The decrease of surface albedo, caused by the poleward retreat of snow and ice cover, is mainly responsible for the increase of net radiation. In short, the surface warming at high latitudes is caused not only by oceanic heating itself but also by the poleward retreat of snow and ice cover which is induced by the oceanic heating. It is of interest that the contribution from the latter process is larger than the contribution from the oceanic heating. For comparison, the surface heat balance components estimated by Budyko [1974] are shown in Figure $5 b$.

The difference in thermal structure of the atmosphere for the models with and without ocean currents is analyzed further in Figure 6. This figure shows the zonally averaged temperature difference between the two models in a latitude- height distribution. Ocean currents have the effect of warming the atmosphere nearly everywhere, except in the stratosphere where cooling occurs. The amount of warming is greatest at high latitudes of the lower troposphere. Previous studies by Manabe [1969] and Manabe et al. [1975] have also shown temperature differences caused by the influence of ocean currents. Their results indicate slight cooling of the equatorial troposphere and less intense warming of the lower troposphere at high latitudes. Since ocean currents remove heat from low latitudes and transport it to higher latitudes, cooling is expected to occur at low latitudes and warming at high latitudes. However, in the present experiment the tropical cooling is missing because the overall warming caused by the poleward retreat of snow cover and sea ice is larger.

One of the factors which may be responsible for the larger polar warming in the present study compared to previous studies is the idealized geography. Because of this idealization, the polar ocean of the present model is entirely open to the penetration of oceản currents from lower latitudes. On the other hand, the polar region of the model with idealized geography used by Manabe [1969] is covered entirely by continent, which prevents the penetration of ocean currents into

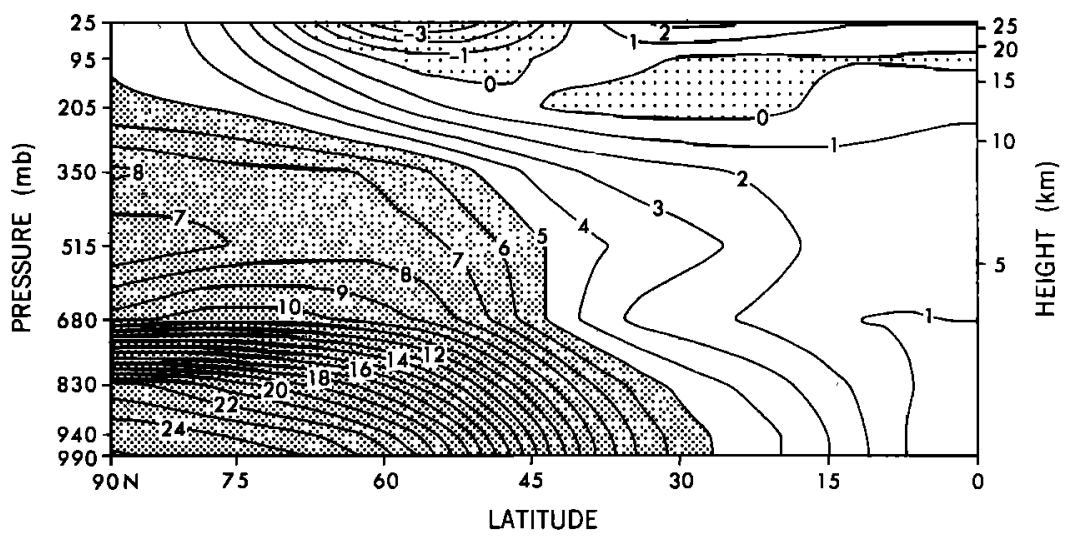

Fig. 6. Latitude-height distribution of the zonally averaged temperature difference (degrees Kelvin) between the model with ocean currents and the model without ocean currents for the normal $\mathrm{CO}_{2}$ case. 


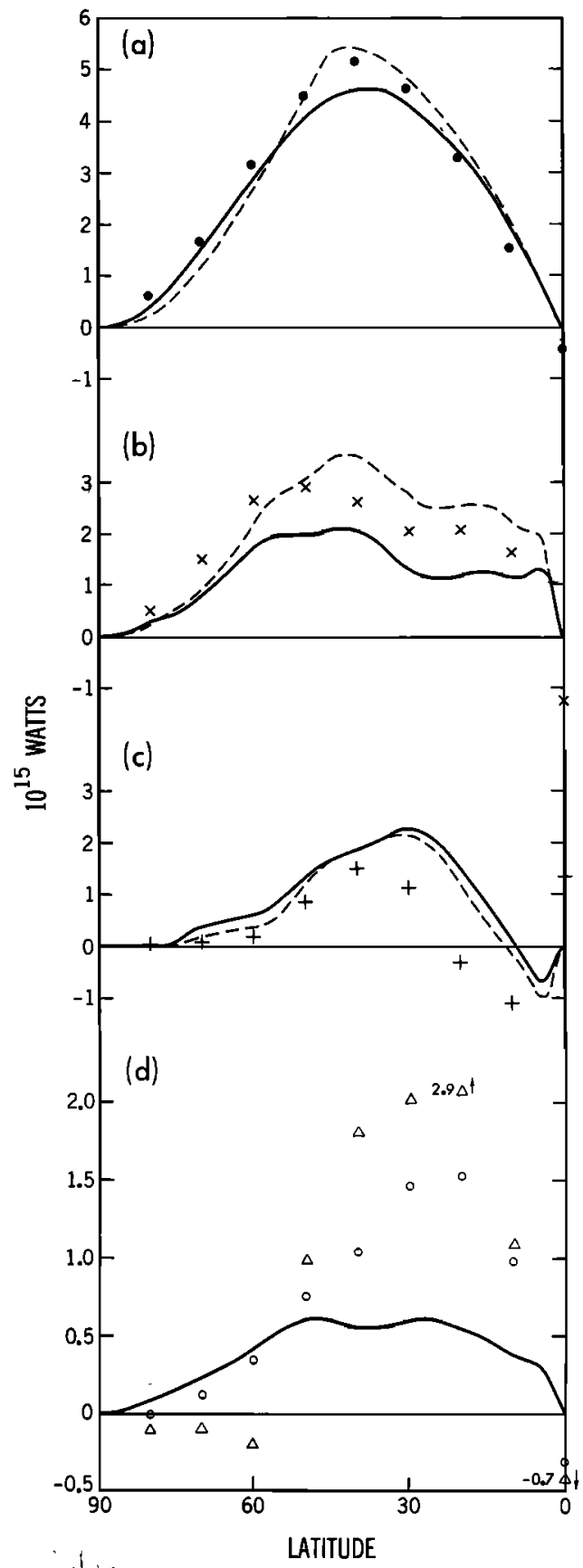

Fig. 7. Vertically integrated poleward transport of energy $\left(10^{15}\right.$ W) in the model with ocean currents (solid lines) and in the model without ocean citrirents (dashed lines) for the normal $\mathrm{CO}_{2}$ case. (a) Total energy transport, $(b)$ transport of dry static energy, $(c)$ latent energy transport, and $(d)$ transport by the ocean. For the convenience of illustration, the scale of the ordinate in Figure $7 d$ is magnified. Observed values, plotted by symbols at $10^{\circ}$ latitude intervals, are compiled by Sellers [1965] following Budyko [1963]. In Figure 7d, circles indicate observed values from Sellers [1965], triàngles indicate observed values from Oort and Vonder Haar [1976]. Since the computational domain of the model covers only one third of the latitude circle, all transport values are multiplied by a factor of 3 for comparison with the observed estimates.

high latitudes. The model used by Manabe et al. [1975] has a global computational domain with realistic geography. Therefore, the polar region in the southern hemisphere is covered by the Antarctic continent. In the "northern hemisphere of their model, the polar region is occupied by the Arctic Ocean which is less open to the ocean currents from low latitudes than the polar ocean of the present model. Therefore, it is reasonable that northward heat transport by ocean currents poleward of $60^{\circ} \mathrm{N}$ is larger for the present model than for the other two models used in the previous studies. These discussions suggest that the polar warming caused by oceanic heat transport may be exaggerated in the present model because of the idealized geography.

Poleward energy transport occurs in both ocean and atmosphere. By comparing the distributions of energy transport in the models with and without ocean currents, we can evaluate how oceanic heat transport influences the total energy transport in the coupled ocean-atmosphere system. In the coupled system, poleward energy transport occurs by the following processes: (1) atmospheric transport of dry static energy, which is the sum of enthalpy $\left(c_{p} T\right)$, potential energy $(\phi)$, and kinetic energy $(k) ;(2)$ atmospheric transport of latent energy $(L r)$; and (3) heat transport by ocean currents. Here, $T, \phi$, and $r$ represent temperature, geopotential height, and water vapor mixing ratio, respectively; $c_{p}$ denotes the specific heat of air under constant pressure; and $L$ the latent heat of evaporation. The vertically integrated meridional energy transports by each of these three processes are shown separately in Figures $7 b, 7 c$, and $7 d$ for both the ocean-atmosphere model and the mixed layer ocean-atmosphere model. Poleward energy transport in Figure $7 a$ in the ocean-atmosphere model is accomplished by all three processes identified above, whereas in the mixed layer ocean-atmosphere model only processes 1 and 2 contribute to the energy transport. Therefore, it is surprising that the total poleward energy transport shown in Figure $7 a$ is actually reduced in middle latitudes when the addditional transport by ocean currents is included. In this case, the reduction of dry static energy transport by the atmosphere in Figure $7 b$ is larger than the addition of energy transport by the ocean in Figure $7 d$. (Note that the scale of the ordinate in Figure $7 d$ is expanded). The albedo feedback effect is an important factor in this reduction. The increased heating which occurs at high latitudes by the oceanic heat transport is amplified by the albedo feedback effect. This reduces the meridional gradient of temperature. As a result, the transport of dry static energy by the atmosphere in Figure $7 b$ is reduced in the model with ocean currents.

In the previous study by Manabe et al. [1975] using a global model, the total energy transport remained unchanged when the additional energy transport by the oceans was included in the model. This occurred because the additional contribution of oceanic heat transport was counter balanced by the reduction of dry static energy transport by the model atmosphere.

Figure 7 also indicates that the processes of meridional energy transport in the models have distributions that are qualitatively similar to estimates for the actual atmosphere from Sellers [1965]. However, as Figure $7 c$ indicates, the meridional transport of latent energy in both model atmospheres is significantly different from the observed transport; particularly at low latitudes. This is consistent with the failure of the model to simulate correctly the precipitation rates, especially in the tropics and at high latitudes. As pointed out by $W e$ therald and Manabe [1981], model precipitation is systematically underestimated in the tropics and overestimated at high latitudes compared to the observed rates. This model bias is consistent with the overestimation of the poleward transport of latent eniergy. Nevertheless, the atmospheric transport of 


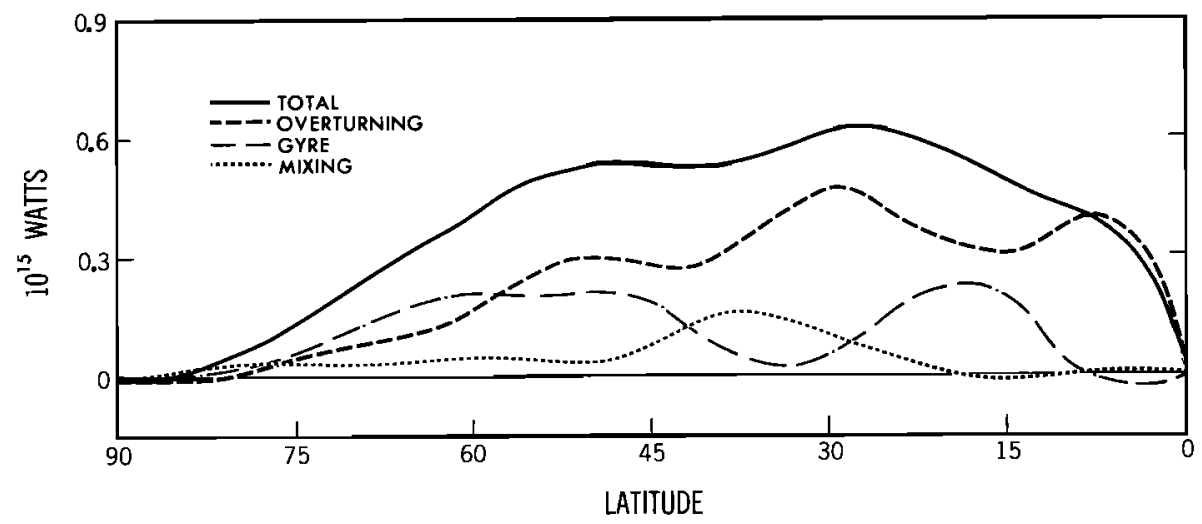

Fig. 8. Components of the poleward oceanic heat transport $\left(10^{15} \mathrm{~W}\right)$ in the model with ocean currents as a function of latitude for the normal $\mathrm{CO}_{2}$ case.

moist static energy (i.e., the sum of dry static energy and latent heat) in the ocean-atmosphere model is in good agreement with the observed transport. Another discrepancy occurs in the energy transport by ocean currents shown in Figure $7 d$. The poleward oceanic heat transport in the subtropics is substantially smaller than Sellers' estimate of the actual transport indicated in this figure and is much smaller than the independent estimate obtained by Oort and Vonder Haar [1976]. The subtropical maximum of oceanic heat transport results from the enhancement of meridional overturning by the wind driven Ekman drift in the subtropical ocean [Bryan and Lewis, 1979]. An improvement in the modeling of the Ekman boundary layer and vertical thermal mixing by subgrid scale eddies in the interior of the ocean may be required in order to obtain a more realistic oceanic heat transport. In the polar region, where the effect of oceanic heat transport is particularly important because of the surface albedo feedback process, the model transport is larger than the estimates of the actual transport shown in Figure $7 d$. This is consistent with the earlier speculation that the present model may exaggerate the oceanic heat transport into the polar region because of the idealized geography.

To gain some insight into the mechanisms of meridional heat transport by the ocean in the model, it is necessary to consider the components of the transport process. As indicated by Bryan [1969], the average meridional heat transport $H_{0}$, across a given latitude in the ocean may be written

$$
H_{0}=\rho c_{p}\left(\bar{v} \bar{\theta}+\overline{v^{\prime} \theta^{\prime}}+A_{H} a^{-1} \partial \bar{\theta} / \partial \phi\right)
$$

where $(\overline{)} \text { ) indicates zonal average and ( })^{\prime}$ indicates deviation from zonal average, $v$ and $\theta$ are velocity and potential temperature, respectively, $A_{H}$ is the lateral coefficient of turbulent diffusion, $\rho$ is density, $a$ is the earth's radius, and $\phi$ is latitude. The term $\bar{v} \bar{\theta}$ in the expression for $H_{0}$ is the component of transport associated with overturning in the meridional plane. This term is important only when zonally averaged values of velocity and temperature are correlated. The term $\overline{v^{\prime} \theta^{\prime}}$ is the transport due to correlations of velocity and temperature at the same level and is associated with the major mid-latitude gyres. The last term, $A_{H} a^{-1} \partial \bar{\theta} / \partial \phi$, represents transport by lateral mixing. Figure 8 shows the vertically integrated meridional energy transport by each of these processes for the oceanatmosphere model. At low latitudes, poleward heat transport in the model ocean is accomplished mainly by meridional overturning. (Recently, Bryden and Hall [1980] estimated the poleward heat transport in the Atlantic at $25^{\circ}$ latitude and found that the contribution from meridional overturning accounts for most of the transport.) Poleward of about $50^{\circ}$ latitude where the albedo feedback effect is important, the dominant mechanisms are the horizontal gyre component and overturning, whereas the mixing component is relatively less important. The latitudinal distributions of the various components shown in Figure 8 are qualitatively similar to those obtained by Bryan and Lewis [1979] from their ocean model. Their study discusses in detail the mechanisms responsible for the oceanic heat transport.

\section{Climate Sensitivity}

As described in section 3 , the influence of oceanic heat transport upon the sensitivity of climate is investigated by comparing the $\mathrm{CO}_{2}$-induced temperature changes of two model climates.

The zonally averaged temperature response of the oceanatmosphere model to the quadrupling of $\mathrm{CO}_{2}$ is shown in Figure 9 in a latitude-height distribution. In the model atmosphere the troposphere has higher temperatures and the stratosphere has lower temperatures as a result of increasing the $\mathrm{CO}_{2}$ content. These features are in agreement with the results of earlier studies [e.g., Manabe and Wetherald, 1967, 1975]. The tropospheric temperature differences are particularly large near the earth's surface at high latitudes where the poleward shift of the snow and sea ice margins reduces the surface albedo and enhances the $\mathrm{CO}_{2}$-induced warming. The warming of the surface layer is much smaller at low latitudes than at high latitudes of the model. Because of stable stratification, the layer of large temperature differences tends to be confined to the lower model troposphere at high latitudes. On the other hand, the $\mathrm{CO}_{2}$-induced warming at low latitudes spreads over the entire model troposphere due to intense vertical mixing through the moist convective process. For further discussion of the physical mechanisms responsible for the $\mathrm{CO}_{2}$-induced temperature change in a model atmosphere, refer, for example, to Manabe [1983], Manabe and Wetherald [1980], and Held [1978].

In the model ocean, zonally averaged temperatures are higher everywhere due to the atmospheric $\mathrm{CO}_{2}$ increase. The warming in the deep ocean of $7.5^{\circ} \mathrm{C}$ is approximately equal to the large warming of the ocean surface at about $65^{\circ}-70^{\circ}$ latitude where the stratification is relatively weak and the heat anomaly can penetrate from the surface into the deeper ocean. For this reason, the $\mathrm{CO}_{2}$-induced warming of the deep ocean is significantly larger than the area averaged warming of the 


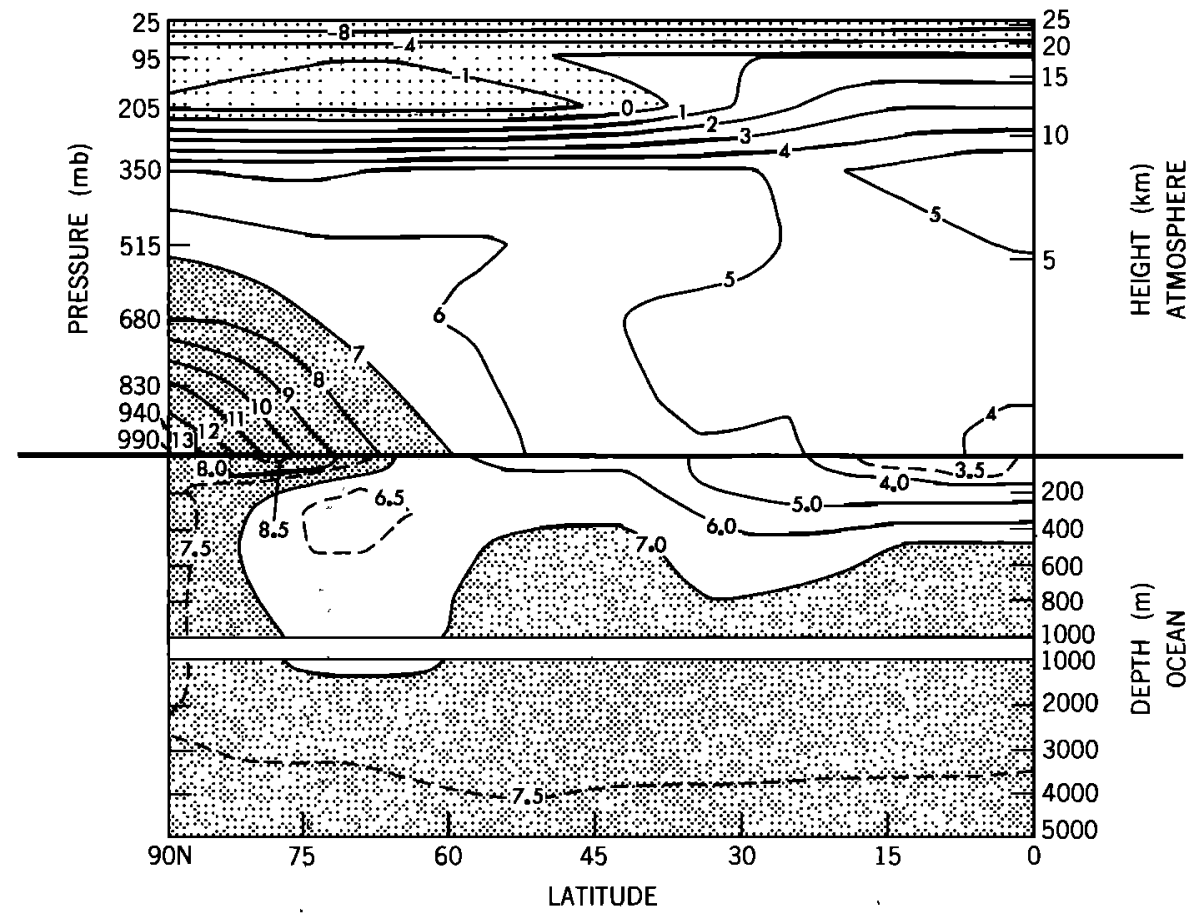

Fig. 9. Latitude-height distribution of the zonally averaged temperature change (degrees Kelvin) due to quadrupling the atmospheric $\mathrm{CO}_{2}$ content in the mpdel with ocean currents.

ocean surface layer. (See section 8 for a discussion of the paleoclimatic implications of this result.) The smallest temperature increases in the ocean occur in surface tropical waters where the warming in the overlying atmosphere is relatively small. Largest temperature increases at the ocean surface occur not at the pole but in a very shallow layer near $75^{\circ}$ latitude. In this region the stable stratification of the halocline, which is caused by an excess of precipitation over evaporation, partially insulates the surface water from the deeper ocean water.

In Figure 10, the increases of zonally averaged surface air temperature caused by the quadrupling of $\mathrm{CO}_{2}$ content are shown for the model with ocean currents and for the model without ocean currents. According to this figure, the $\mathrm{CO}_{2}$-induced warming of surface air temperature is much smaller in the model with ocean currents. This implies that oceanic heat transport markedly reduces the sensitivity of a model climate, particularly at high latitudes. To investigate the physical mechanisms responsible for the difference in sensitivity between the two models, the influences of various physical processes upon the radiation budgets of the two models are investigated. In more specific terms, the contributions of the $\mathrm{CO}_{2}$-induced change of various relevant variables upon the radiative flux at the top of each model atmosphere are evaluated. The variables considered here include surface albedo, atmospheric temperature, water vapor mixing ratio, and $\mathrm{CO}_{2}$ concentration in air. The results from the models with. and without ocean currents are compared with one another to determine the effect of oceanic heat transport upon the sensitivity of the model climate. A detailed account of this analysis follows.

The change in the net downward radiation $R$ at the top of the model atmosphere in response to increasing the $\mathrm{CO}_{2}$ content is given by

$$
\delta R=\delta S-\delta F
$$

where $S$ and $F$ are changes of net downward solar radiation and net upward terrestrial radiation at the top of the model atmosphere, respectively. $S$ and $F$ may be approximated as

$$
\begin{gathered}
\delta S \approx \delta_{\mathrm{CO}_{2}} S+\delta_{r} S+\delta_{a} S \\
\delta F \approx \delta_{\mathrm{CO}_{2}} F+\delta_{r} F+\delta_{T} F
\end{gathered}
$$

where $\delta_{x} S$ and $\delta_{x} F$ denote changes in $S$ and $F$ in response to a change in quantity $x$ when it is assumed that all other relevant quantities do not change. The subscripts $\mathrm{CO}_{2}, T, r, \alpha$ denote atmospheric carbon dioxide content, atmospheric temperature, water vapor mixing ratio, and surface albedo for solar radiation, respectively. From physical considerations, we have $\delta_{a} F=\delta_{T} S=0$. Because of the nonlinear dependence of $S$ and

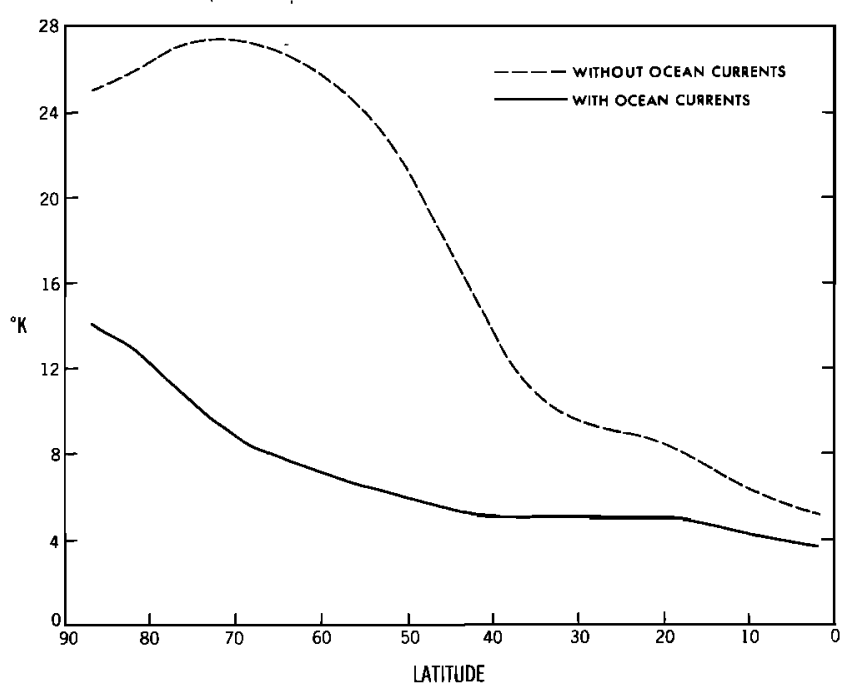

Fig. 10. Latitudinal variation of the change of zonally averaged surface air temperature (degrees Kelvin) caused by quadrupling the atmospheric $\mathrm{CO}_{2}$ content for both the model with ocean currents (solid line) and the model without ocean currents (dashed line). 
TABLE 1. $\mathrm{CO}_{2}$-induced Partial Changes in Radiative Flux Components, $\delta S, \delta F, \delta R\left(\mathrm{~W} \mathrm{~m}^{-2}\right)$ at the Top of the Ocean-Atmosphere Model Caused by Separate Changes in Various Relevant Factors $\mathrm{CO}_{2}, T, r, \alpha$

\begin{tabular}{rcrccr}
\hline & $\mathrm{CO}_{2}$ & $T$ & $r$ & $\alpha$ & \multicolumn{1}{c}{$\sum$} \\
\hline$\delta S$ & 0.3 & - & 1.0 & 3.6 & 4.9 \\
$-\delta F$ & 3.2 & -14.5 & 6.2 & $\frac{-}{3.6}$ & -5.1 \\
$\delta R$ & 3.5 & -14.5 & 7.2 & 3.6 & -0.2 \\
\hline
\end{tabular}

The sum of all the partial changes is denoted by $\sum$.

$F$ on these quantities, the sums of all parts are not exactly equal to $\delta S$ and $\delta F$. The following expression for $\delta_{a} S$ is an example of the procedure used to compute each quantity on the right hand side of (3) and (4):

$$
\delta_{\alpha} S=S\left({ }^{1} \mathrm{CO}_{2},\left\{{ }^{1} r_{i}\right\},{ }^{4} \alpha\right)-S\left({ }^{1} \mathrm{CO}_{2},\left\{{ }^{1} r_{i}\right\},{ }^{1} \alpha\right)
$$

where superscripts 1 and 4 indicate the data from the experiments with normal and 4 times the normal atmospheric $\mathrm{CO}_{2}$ concentrations, and $\left\{r_{i}\right\}$ indicates values of water vapor mixing ratio at all finite difference levels of the model. In other words, (5) indicates that the influence of the change of surface albedo, $\alpha$, on the solar radiation is evaluated by changing $\alpha$ while all other quantities are kept unchanged.

The results of this analysis for the model with ocean currents are presented in Table 1 . It contains area averaged partial changes of $S, F$, and $R$ resulting from the changes in $\mathrm{CO}_{2}$, $T, r$, and $\alpha$ in response to increasing the $\mathrm{CO}_{2}$ content. According to this table, the change of surface albedo has a positive contribution to $\delta R$, which indicates the positive feedback effect of snow and sea ice. The $\mathrm{CO}_{2}$-induced increase in the infrared opacity of the atmosphere reduces the outgoing terrestrial radiation at the top of the atmosphere and contributes positively to $\delta R$. In addition, the $\mathrm{CO}_{2}$-induced warming of the atmosphere is accompanied by a general increase of the absolute humidity and the infrared opacity of the atmosphere. This further reduces the outgoing terrestrial radiation $\left(\delta_{r} F=\right.$ $-6.2<0$ ), increases the atmospheric absorption of solar radiation $\left(\delta_{r} S=1.0>0\right)$ and contributes positively to $\delta R$. These positive contributions are counter balanced by an increase of the upward flux of terrestrial radiation resulting from the atmospheric warming $\left(\delta_{T} F=14.5>0\right)$. A comparison of the net contributions in the bottom row of Table 1 shows that the area averaged $\delta_{a} R$ is smaller than $\delta_{r} R$. This result is in agreement with the previous study of Manabe and Wetherald [1980]. It is of particular interest that $\delta_{\mathrm{CO}_{2}} R$ is significantly smaller than $\delta_{r} R$ even though the increase of the atmospheric $\mathrm{CO}_{2}$ is the original cause of the atmospheric warming. The $\sum$ column in Table 1 indicates that the sum of the partial changes of $\delta S$ and $\delta F$, which are computed from (3) and (4), are not equal in magnitude because of nonlinear interactions among the relevant quantities.

To appreciate the influence of the surface albedo change for the model with ocean currents, it is useful to examine its variation with latitude in contrast to the variation of other components by use of Figure $11 a$. In this figure, the scale of the abscissa is proportional to the sine of latitude and is indicative of the area from the pole to a given latitude circle. Thus, the area under each curve is proportional to the contribution of each quantity. From this figure it is clear that $\delta_{2} R$ is the dominant positive contribution at high latitudes, whereas $\delta_{\mathrm{CO}_{2}} R$ and $\delta_{r} R$ have a more uniform, positive distribution at all latitudes. $\delta_{2} R$ is significant from about $55^{\circ}$ latitude to the pole where the surface albedo is changed by the reduction of snow and ice cover. This is also indicated by Figure 12, which shows the difference of zonally averaged planetary albedo between the increased $\mathrm{CO}_{2}$ and normal $\mathrm{CO}_{2}$ climates.

In the model without ocean currents, the contribution of the albedo feedback effect is very large at high latitudes as indicated by Figure $11 b$. Accordingly, the area averaged contribution of $\delta_{a} R$ is larger than the area averaged value of either $\delta_{\mathrm{Co}_{2}} R$ or $\delta_{r} R$ presented in Table 2 . In this model the zonally averaged surface air temperature is significantly lower and the snow and ice cover is more extensive than in the model with ocean currents as discussed earlier (see Figure 3). Therefore, the $\mathrm{CO}_{2}$-induced retreat of snow and sea ice margins occurs at a lower latitude than the model with ocean currents. This difference is depicted in Figure 12 which shows the latitudinal distributions of the $\mathrm{CO}_{2}$-induced changes of zonal mean planetary albedo from both models. Since both insolation and the length of latitude circles increase with decreasing latitude, the $\mathrm{CO}_{2}$-induced poleward retreat of snow cover has a much larger impact on the reflected solar radiation than in the model with ocean currents. This is clearly indicated in Figure $11 b$ as the large area under the $\delta_{a} R$ curve at high latitudes. In summary, the difference in magnitude of the albedo feedback effect is one of the key factors which accounts for the higher sensitivity of the model without ocean currents.

The components of the poleward transport of energy are shown in Figure 13 for the ocean-atmosphere model for the cases of normal $\mathrm{CO}_{2}$ and increased $\mathrm{CO}_{2}$ concentrations. Significant features of the energy transport for the normal $\mathrm{CO}_{2}$ case have been discussed in the previous section (cf. discussion of Figure 7). According to Figure 13b, the poleward transport of dry static energy is reduced, except in the tropics, as a result of quadrupling the $\mathrm{CO}_{2}$ concentration in the model atmosphere. As discussed by Manabe and Wetherald [1975, 1980], this results from the $\mathrm{CO}_{2}$-induced reduction of meridional temperature gradient in the lower model troposphere. The poleward transport of latent energy in Figure $13 c$ increases, except in the tropics, as a result of increasing the $\mathrm{CO}_{2}$ content. This increase of transport is caused by a general increase of atmospheric water vapor associated with the $\mathrm{CO}_{2}$-induced warming of the atmosphere. In the model tropics the equatorward flux of latent energy is larger for the increased $\mathrm{CO}_{2}$ case, in agreement with previous studies [e.g., Manabe and Wetherald, 1975]. As shown in Figure 13d, the contribution by ocean currents is reduced slightly at most latitudes by increasing the atmospheric $\mathrm{CO}_{2}$. (Note that the scale of the ordinate in Figure $13 d$ is expanded.) This indicates that the change in oceanic heat transport slightly reduces the $\mathrm{CO}_{2}$-induced warming at high latitudes. However, the influence of this reduction upon the sensitivity of the model climate is small.

An interesting aspect of increasing $\mathrm{CO}_{2}$ is that the total energy transport in Figure $13 a$ is unchanged at low latitudes and only slightly reduced at high latitudes from the normal $\mathrm{CO}_{2}$ case. This occurs despite the reduction in meridional temperature gradient in both the atmosphere and ocean. Changes in poleward transport of dry static energy in Figure $13 b$ are almost completely offset by changes in the transport of latent energy in Figure $13 c$, while the reduction of energy transport by the ocean is small.

\section{Climate Sensitivity Compared to Previous Studies}

In the previous section the sensitivity of surface air temperature to increasing the atmospheric $\mathrm{CO}_{2}$ concentration was 

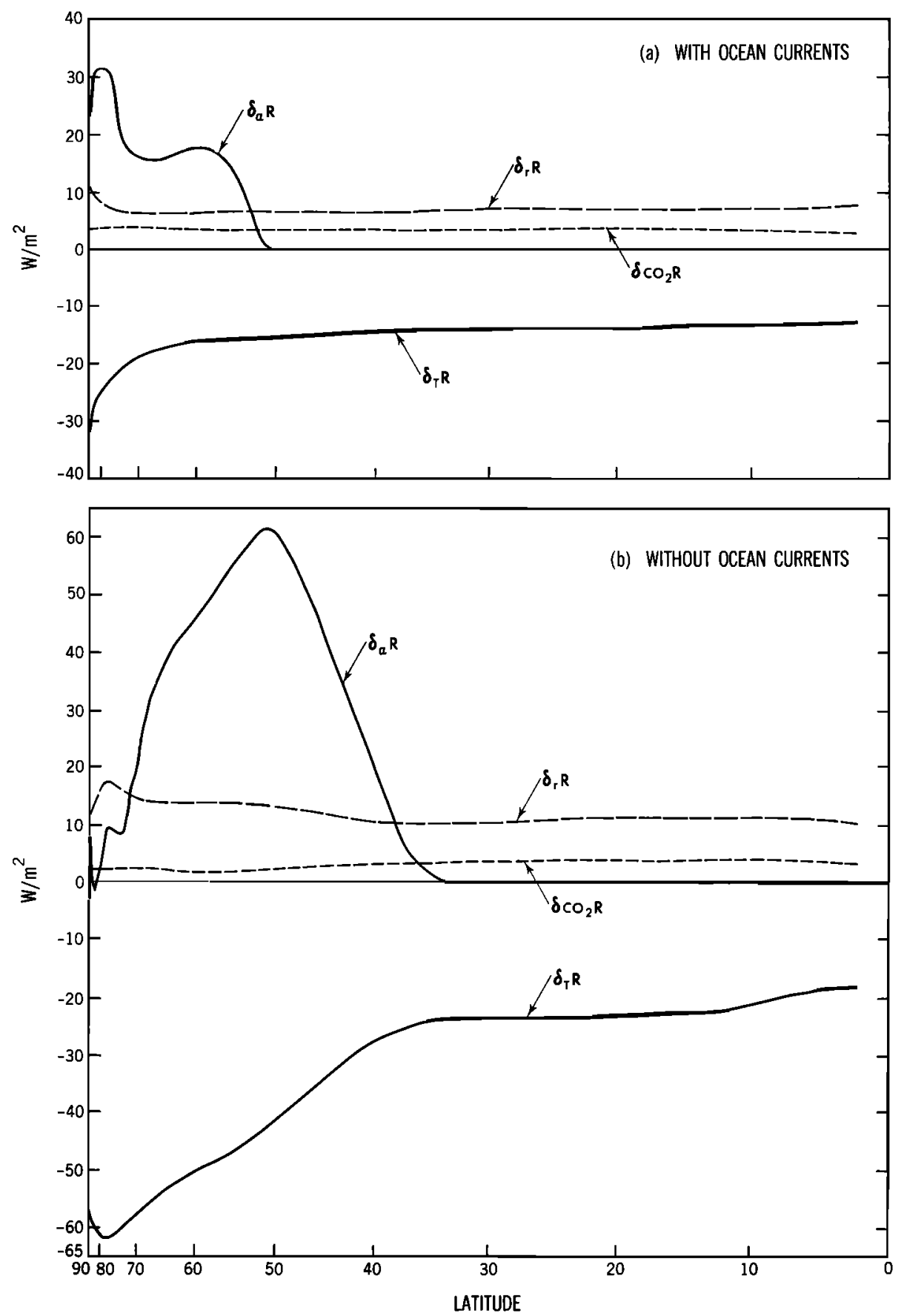

Fig. 11. The latitudinal variation of zonally averaged $\mathrm{CO}_{2}$-induced changes in net radiative fux, $\delta R\left(\mathrm{~W} / \mathrm{m}^{2}\right)$ at the top of the model atmosphere caused by separate changes in various relevant factors $\mathrm{CO}_{2}, T, r, \alpha$ for $(a)$ the model with ocean currents $(b)$ the model without ocean currents.

discussed. It is of interest to compare the sensitivity obtained in this study with that of previous studies, in order to place the present results in proper perspective. The characteristics of the models used in three recent studies are given in Table 3. For the purpose of identification, the models are denoted by the symbols given in the first column of the table. A common characteristic of the models listed in Table 3 is the use of the spectral transform technique for the dynamical calculation. Since all these models have the same computational resolution, they are chosen for the present intercomparison.

The discussion in the preceding section indicates that the albedo feedback effect has a strong influence upon the sensi- tivity of a model climate. When the $\mathrm{CO}_{2}$ concentration is increased, the warming of the atmosphere is amplified particularly at high latitudes by the change of surface albedo as the snow and ice margin retreats toward the pole. Since the location of the snow and ice margin depends upon the distribution of surface air temperature, it is reasonable that the magnitude of the climate sensitivity will be influenced by the temperature distribution. The dependence of sensitivity upon atmospheric temperature has been noted in the results from simple energy balance models [Budyko, 1969; Suarez and Held, 1979] as well as from general circulation models [Wetherald and Manabe, 1975; Held et al., 1981]. Figure 14 indi- 


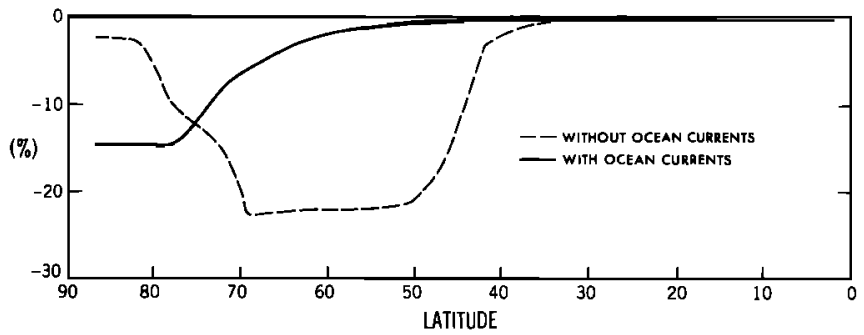

Fig. 12. The $\mathrm{CO}_{2}$-induced changes of zonally averaged planetary albedo (percent) as a function of latitude for the model with ocean currents (solid line) and the model without ocean currents (dashed line).

cates how the sensitivity of surface air temperature depends upon the area averaged surface air temperature of the normal $\mathrm{CO}_{2}$ case for each of the models listed in Table 3. This figure indicates that models which have nearly the same area averaged surface air temperatures have similar sensitivities.

Figure 14 also indicates that, in general, models which have lower surface air temperatures have higher sensitivities. For example, because of the absence of oceanic heat transport, the SM1(A) model used in the present study has much lower surface air temperature and higher sensitivity than the companion SM2(A) model with oceanic heat transport. Although the WM(A) model also does not have oceanic heat transport, it has area averaged surface air temperature which is much higher than the SM1(A) model and is comparable to the SM2(A) model. Accordingly, its sensitivity is similar to the SM2(A) model, but much lower than the SM1(A) model. As Table 3 indicates, the WM(A) model has $1 \%$ larger solar constant and $20 \%$ larger blackness of cirrus clouds than the SM1(A) model. (Otherwise, these two models are identical.) Since the influence of a $10 \%$ increase in cirrus blackness upon the net radiative flux at the top of the model atmosphere is approximately equal to a $1 \%$ increase of the solar constant, the net effect of these two differences is equivalent to a $3 \%$ difference in the solar constant. This is why the surface temperature of the WM(A) model is much higher than the SM1(A) model even though both models lack oceanic heat transport. Because the surface air temperature difference between the WM(A) and the SM1(A) models is comparable to the corresponding difference between the SM2(A) and the SM1(A) models, these discussions suggest that the oceanic heat transport in the SM2(A) model has a warming effect which is approximately comparable to a $3 \%$ increase in the solar constant. (See Wetherald and Manabe [1981] for a discussion of the difference between the two companion models WM(A) and WM(S) and the somewhat lower sensitivity of the MS(S) model with realistic geography.)

The data for the SM3(A) model in Figure 14 illustrates the almost linear dependence of sensitivity upon the area averaged surface air temperature. As Table 3 indicates, the SM3(A) model is identical to the SM1(A) model except that the solar constant is reduced by $0.5 \%$ and the blackness of cirrus clouds

TABLE 2. Same as Table 1, for the Mixed Layer OceanAtmosphere Model

\begin{tabular}{rccccr}
\hline & $\mathrm{CO}_{2}$ & $T$ & $r$ & $\alpha$ & \multicolumn{1}{c}{$\sum$} \\
\hline$\delta S$ & 0.4 & - & 3.0 & 14.7 & 18.1 \\
$-\delta F$ & 2.7 & -30.8 & 8.5 & - & -19.6 \\
$\delta R$ & 3.1 & -30.8 & 11.5 & 14.7 & -1.5 \\
\hline
\end{tabular}

is increased by $20 \%$. The net effect of these two differences is approximately equivalent to a $1.5 \%$ increase of the solar constant. Therefore, this model has a significantly higher area averaged temperature and lower sensitivity than the SM1(A) model, confirming the almost linear relationship mentioned above. To summarize, the results in Figure 14 suggest that the different sensitivities of the various spectral models discussed here can be attributed mostly to the differences in the contribution from the albedo feedback process.

It has been shown that a model with oceanic heat transport has a lower sensitivity of climate than a model without ocean currents. Therefore, one is tempted to conclude that previous studies using models without ocean currents [e.g., Wetherald and Manabe, 1981; Manabe and Stouffer, 1980] have overestimated the sensitivity. Before doing so, however, one should examine the surface temperature of the model atmosphere, which plays a key role in determining the sensitivity of climate as discussed above. In view of the uncertainties in basic parameters such as the solar constant, optical properties of clouds, and snow/ice albedo, it is not surprising that some of the models without ocean currents in previous studies obtained suface temperature distributions that correspond closely to the observed distributions. (The observed area averaged

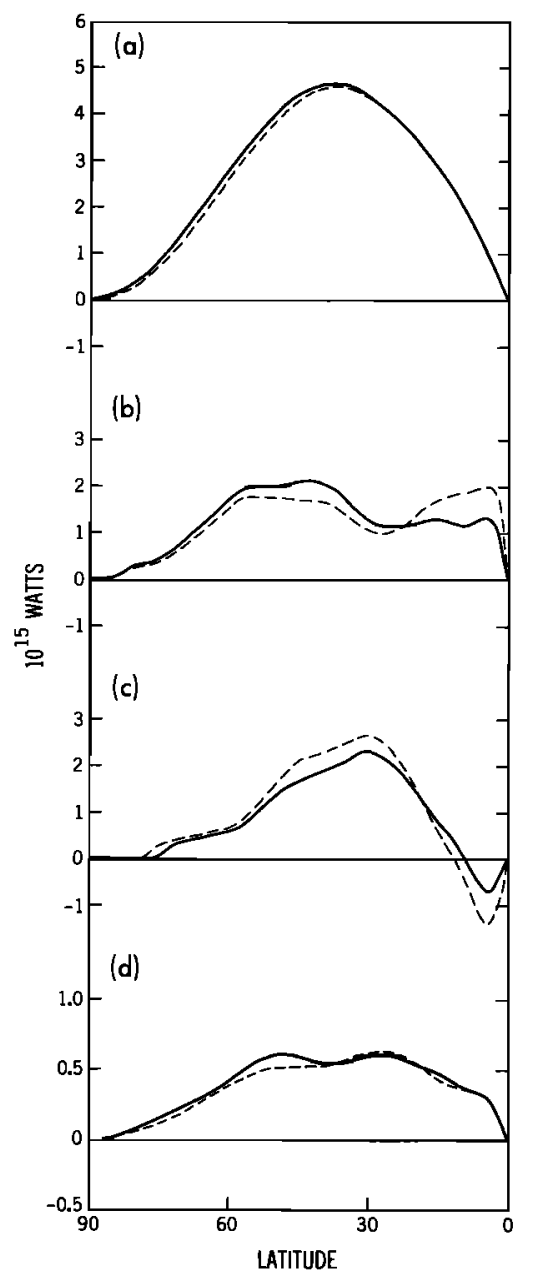

Fig. 13. Vertically integrated poleward transport of energy $\left(10^{15}\right.$ W) in the model with ocean currents for the normal $\mathrm{CO}_{2}$ case (solid lines) and the increased $\mathrm{CO}_{2}$ case (dashed lines). (a) Total energy transport, $(b)$ transport of dry static energy, $(c)$ latent energy transport, and $(d)$ transport by the ocean. The scale of the ordinate in Figure $13 d$ is magnified. All transport values of the models are multiplied by a factor of three, as indicated in Figure 7. 
TABLE 3. The Characteristics of Spectral Climate Models Used for Recent Studies of $\mathrm{CO}_{2}$-Climate Sensitivity

\begin{tabular}{lcccccccc}
\hline Model & Insolation & $\begin{array}{c}\text { Colar } \\
\left(\mathrm{W} / \mathrm{m}^{2}\right)\end{array}$ & $\begin{array}{c}\text { Cirrus } \\
\text { Blackness }\end{array}$ & $\begin{array}{c}\text { Computa- } \\
\text { tional } \\
\text { Domain }\end{array}$ & Geography & Atmosphere & Ocean & Reference \\
\hline SM1(A) & annual & 1356 & $80 \%$ & $1 / 6$ globe & idealized & spectral GCM & mixed layer & present study \\
SM2(A) & annual & 1356 & $80 \%$ & $1 / 6$ globe & idealized & spectral GCM & full ocean & present study \\
SM3(A) & annual & 1349 & $100 \%$ & $1 / 6$ globe & idealized & spectral GCM & mixed layer & present study \\
WM(A) & annual & 1370 & $100 \%$ & $1 / 6$ globe & idealized & spectral GCM & mixed layer & Wetherald and Manabe $[1981]$ \\
WM(S) & seasonal & 1370 & $100 \%$ & $1 / 6$ globe & idealized & spectral GCM & mixed layer & Wetherald and Manabe [1981] \\
MS(S) & seasonal & 1356 & $100 \%$ & global & realistic & spectral GCM & mixed layer & Manabe and Stouffer $[1980]$ \\
\hline
\end{tabular}

surface air temperature is indicated in Figure 14.) Therefore, it would not necessarily be correct to conclude that the results of all previous studies which neglect the effect of oceanic heat transport have overestimated the climate sensitivity.

\section{Transient Response of Climate}

In the present study of climate change, we have discussed differences between the equilibrium states of a model with normal $\mathrm{CO}_{2}$ and increased $\mathrm{CO}_{2}$ concentrations. However, the equilibrium state of climate response to increased $\mathrm{CO}_{2}$ will not be reached for a millenia or longer, mainly because of the large thermal inertia of the oceans. Recently, Schneider and Thompson [1981] suggested that the distributions of the equilibrium response of climate may be quite different from the distributions of the transient response to increasing the $\mathrm{CO}_{2}$ concentration of the atmosphere. Therefore, it is worthwhile to compare the equilibrium and transient responses of the model climates. Such a comparison has recently been made and is briefly described by Bryan et al. [1982]. In this section, the results from their study are discussed in further detail so that one can properly appreciate the implication of the results from the equilibrium sensitivity study described in this paper.
To evaluate the transient response of climate, Bryan et al. used a coupled ocean-atmosphere model which is similar to the model used for the present study. They perturbed the equilibrium climate of the coupled model with normal $\mathrm{CO}_{2}$ concentration by a sudden fourfold increase in the atmospheric $\mathrm{CO}_{2}$ concentration. The atmospheric and oceanic components of the model were time integrated in a synchronous mode, as opposed to the nonsynchronous, economical method discussed in section 3 to obtain climate equilibrium. To evaluate the transient response for comparison with the equilibrium response of the model, Byran et al. defined the fractional response of temperature as

$$
R=\frac{T-T_{0}}{T_{\infty}-T_{0}}
$$

where $T$ is the area averaged temperature, $T_{0}$ is the initial equilibrium value from the normal $\mathrm{CO}_{2}$ case, and $T_{\infty}$ is the final equilibrium value for a fourfold increase in atmospheric $\mathrm{CO}_{2}$. Figure 15 illustrates the latitude-time distributions of the fraction response, $R$, of the zonally averaged surface air temperature separately over ocean and continent. This figure indicates that the fractional response of surface air temperature is

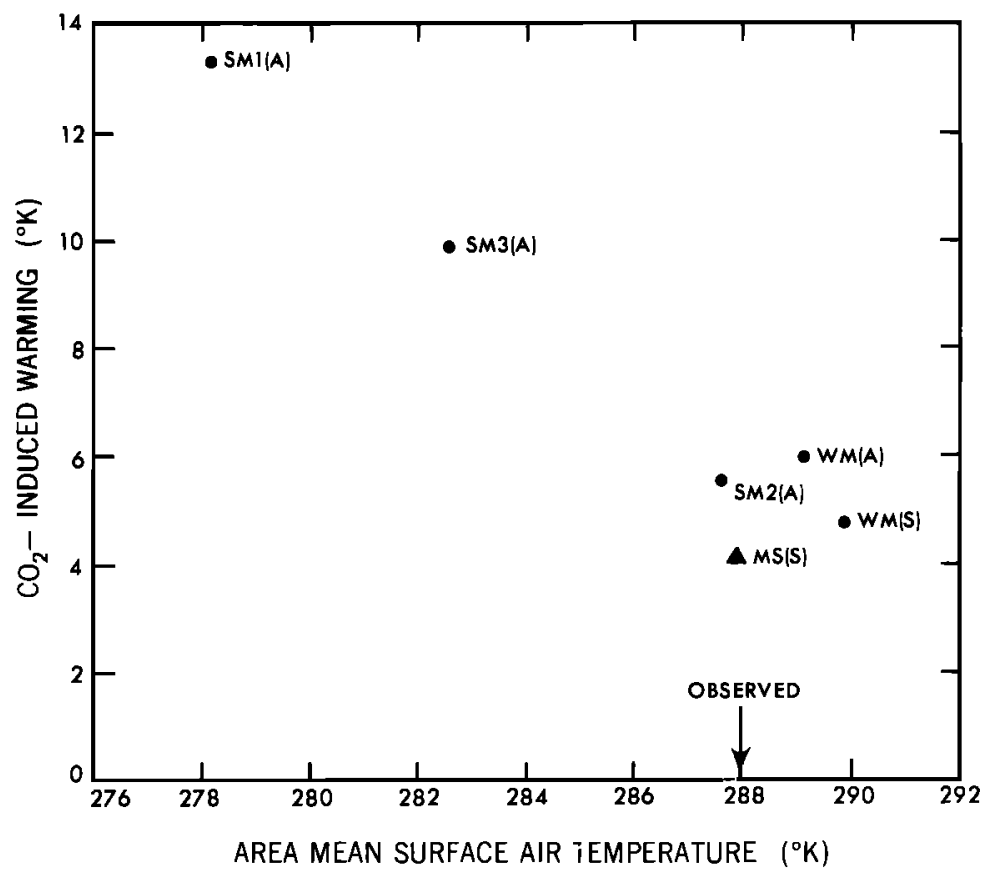

Fig. 14. The sensitivity of area mean surface air temperature (degrees Kelvin) to quadrupling the atmospheric $\mathrm{CO}_{2}$ content for various climate models showing its correspondence to the area mean surface air temperature of the normal $\mathrm{CO}_{2}$ case. A description of the symbols is given in Table 3. Solid dots are plotted for the models having limited computational domain with idealized geography; the triangle indicates the model that has global domain with realistic geography. The observed value of area mean surface air temperature is indicated for reference. 

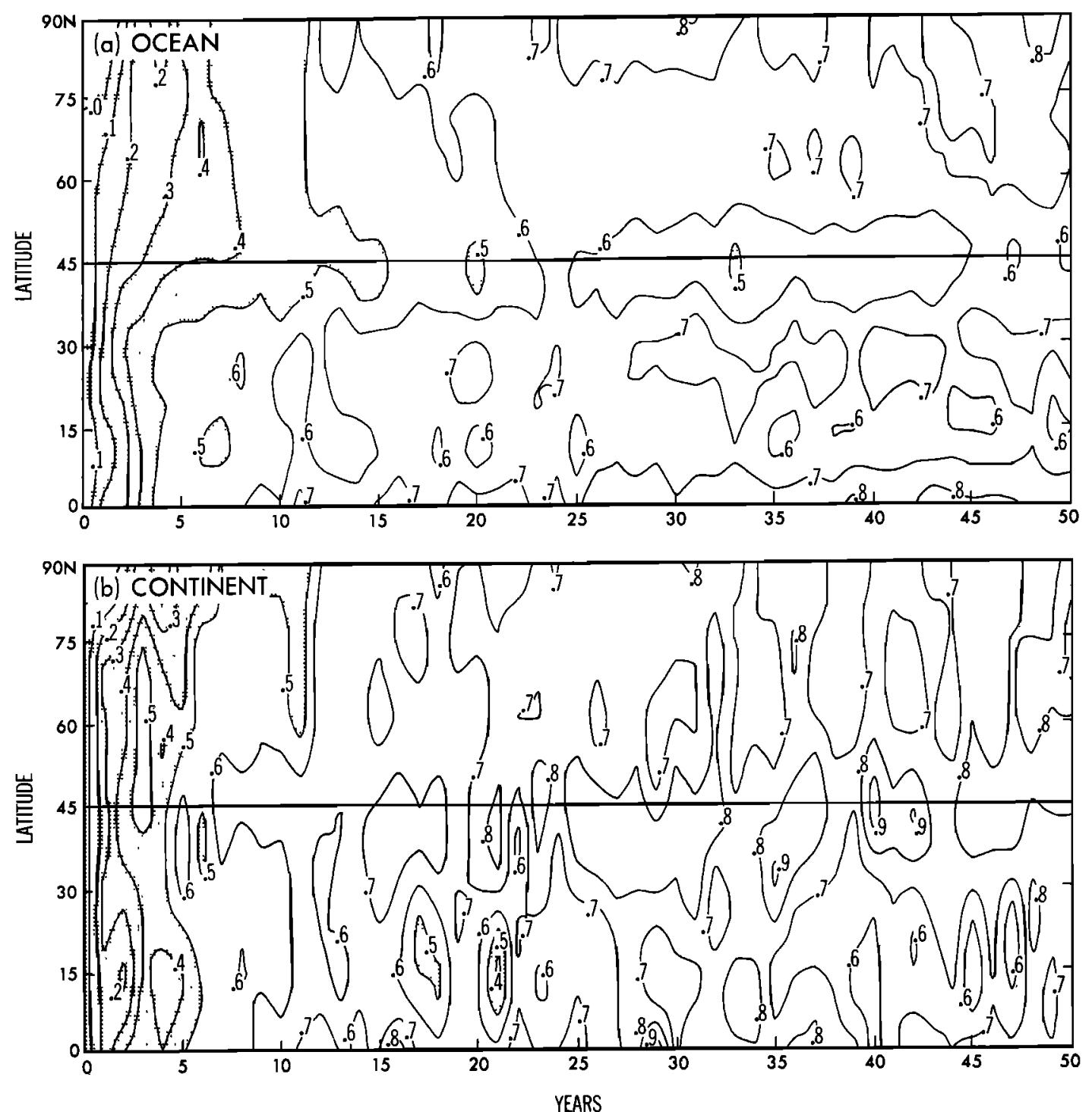

Fig. 15. The latitude-time distributions of fractional response of zonally averaged surface air temperature over (a) ocean and $(b)$ continent.

initially more rapid in the tropics than at high latitudes. However, the fractional response becomes nearly uniform with respect to latitude after about 10 years over the continent and about 25 years over the ocean. This result implies that sensitivity studies of climate equilibrium can be used as an approximate guide for predicting the latitudinal pattern of surface temperature trends provided that the characteristic time scale of $\mathrm{CO}_{2}$ increase is longer than 25 years.

Upon further examination of Figure 15, one notes slight differences between ocean and continent in the fractional response of surface air temperature. Because of the difference in thermal inertia, oceanic response lags behind the continental response. (The fractional responses of area mean surface air temperature are 0.75 and 0.67 over land and ocean, respectively, when they are averaged over the period from 30 to 50 years of the integration.) Furthermore, one notes small but systematic latitudinal variations in fractional response over both ocean and continent. This is a subject for future study.

To examine the vertical and latitudinal distribution of the transient response, Figure 16 is presented. Figure $16 a$ is the zonally averaged temperature change in the atmosphere and upper ocean for the transient response study. The values shown are temperatures at 25 years minus initial temperatures at each latitude. In addition, the fractional response, $R$, of zonally averaged temperature is given in Figure $16 b$. This figure shows the temperature change of Figure 16a normalized by the total temperature difference between the two equilibrium climates shown in Figure 9. The fractional response for the stratosphere is not shown because $R$ becomes indeterminate in the lower stratosphere where the total $\mathrm{CO}_{2}$-induced temperature change is near zero.

Throughout the troposphere, the fractional response of temperature varies little with latitude. In the shallow surface layer of the ocean, the fractional temperature response also has little latitudinal variation, except at the pole. In this region, sea ice exists at the ocean surface and the underlying seawater, which remains at the freezing point, is insulated from the large temperature increases in the overlying atmosphere. Near the sea ice margin at about $75^{\circ}$ latitude, the $\mathrm{CO}_{2}$-induced warming of the sea surface is limited to a shallow surface layer of water because the stable stratification of the halocline insulates the surface water from the deeper ocean. (The halocline appears because of the excess of precipitation over evaporation as pointed out in section 5.) Because of the influences of sea ice 

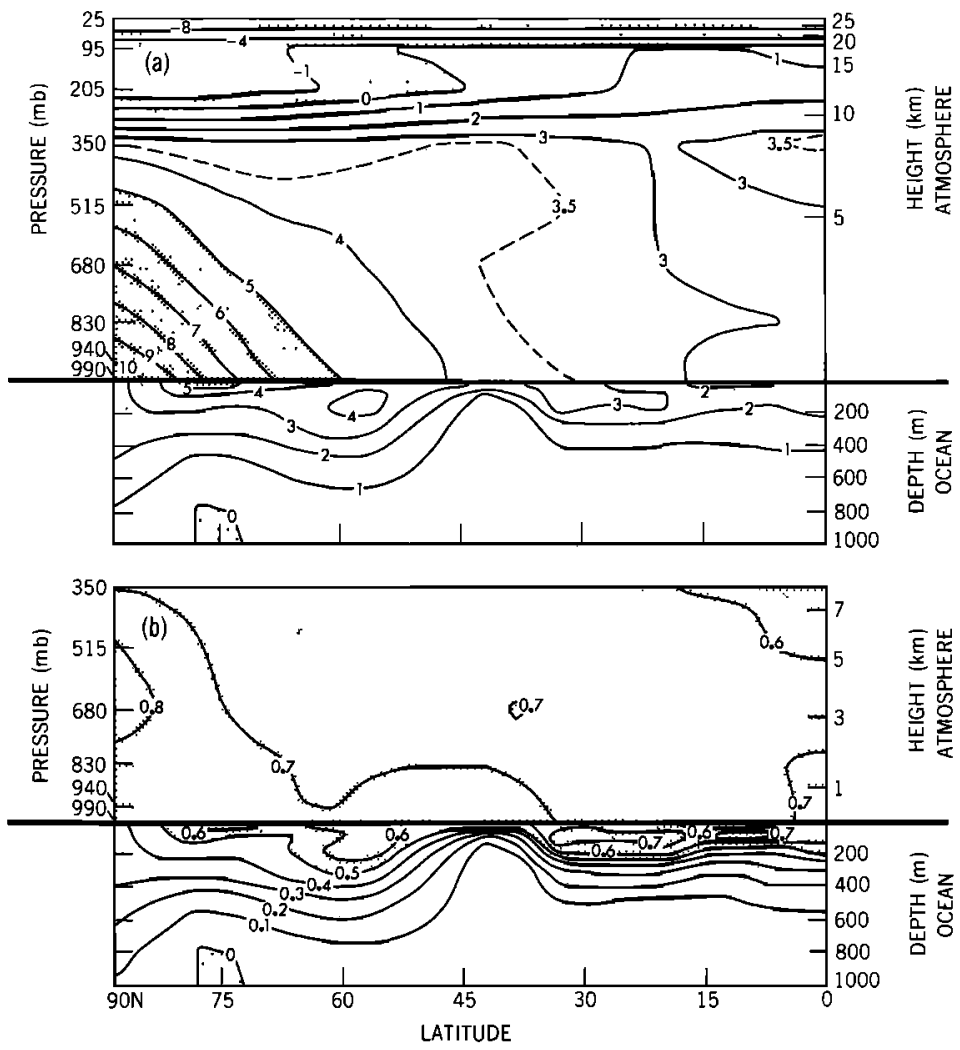

Fig. 16. Latitude-height distributions from the transient response study showing (a) the zonally averaged temperature at 25 years minus initial temperature (degrees Kelvin) and $(b)$ the fractional response of zonally averaged temperature, $R$.

and the halocline, the surface layer of the model atmosphere at high latitudes is almost decoupled from the deep ocean layer of large heat capacity. Thus, the $\mathrm{CO}_{2}$-induced warming of the surface layer of the model atmosphere is particularly large at high latitudes, even though the temperature of the sub-surface ocean layer has hardly increased. Equatorward of $65^{\circ}$ latitude, the penetration of the thermal anomaly is deeper, particularly at about $60^{\circ}$ latitude. However, the fractional temperature response $R$ at the ocean surface is nearly uniform with latitude. On the other hand, the value of $\boldsymbol{R}$ decreases with increasing depth and is very small in the deep ocean of the model. In other words, the latitudinal dependence of zonally averaged temperature of the transient response is similar to that of the equilibrium response in the atmosphere and in the oceanic surface layer, whereas these two responses are quite different from one another in the deep ocean of the model. This result implies that, after approximately 25 years of time integration, the rate of penetration of surface warming into the deep ocean is very slow and accordingly has only a small influence upon the latitudinal distribution of zonally averaged response of temperature in the surface layer of the model ocean. From these results, one can infer that the transient response of zonally averaged surface temperature to a gradual increase of atmospheric $\mathrm{CO}_{2}$ may also resemble the corresponding equilibrium response provided that the time constant for the $\mathrm{CO}_{2}$ increase is larger than 25 years.

Although the results presented in Figure 16 are significant, the quantitative aspects of the transient response study must be considered tentative, pending numerical studies with even more detailed ocean models. Also, the transient behavior of the ocean model must be validated against the observed transient behavior of the actual ocean. Further studies, such as that being conducted by Sarmiento [1983] in the modeling of observed transient tracer data, are essential to gain confidence in the simulation of the transient response of the ocean.

After the publication of the study by Bryan et al. [1982], an error was found in the code which filters short zonal waves for the purpose of computational stability poleward of $45^{\circ}$ latitude in the oceanic component of the coupled model. In this polar region, cyclic continuity was erroneously imposed from one lateral ocean boundary to the other. Therefore, we repeated the transient response experiment after correcting this error. This explains the slight quantitative differences between Figure 16 of this study and Figure 3 of Bryan et al. Fortunately, the main conclusions obtained by Bryan et al. remain valid despite this error.

\section{Conclusions}

The results of this study indicate that the poleward heat transport by ocean currents reduces the sensitivity of climate. The reduced sensitivity is the result of a decrease in the magnitude of the surface albedo feedback process. The oceanic heat transport raises the surface temperature at high latitudes, which shifts the margins of snow cover and sea ice poleward and also reduces the meridional gradient of temperature. The poleward shift of snow and ice margins decreases the climate sensitivity by reducing the contribution from the surface albedo feedback process, since both insolation and length of latitude circles decrease toward the poles. On the other hand, a reduction of the meridional temperature gradient increases the latitudinal change of snow and ice margins in response to a given change of temperature and thus enhances the climate sensitivity because of a larger contribution from the albedo 
feedback process. However, this effect is overshadowed by the effect of the poleward shift of snow and ice margins, resulting in a net reduction of sensitivity due to ocean currents.

Since the poleward heat transport by ocean currents reduces the sensitivity of the model climate as discussed above, one is tempted to speculate that previous studies using models without oceanic heat transport may have overestimated the climatic response to a forcing such as an increase of the atmospheric $\mathrm{CO}_{2}$ concentration. However, such a speculation is not necessarily correct. This is because radiative parameters (e.g., solar constant, and optical properties of clouds) are chosen such that surface air temperatures at high latitudes, and accordingly the coverages of snow and sea ice, are realistic. For this reason, the influence of the albedo feedback process upon the sensitivity of surface air temperature may not be overestimated despite the absence of oceanic heat transport in the models used in these studies.

Because of the large thermal inertia of the ocean, it takes an extremely long time (i.e., several thousand years) before the equilibrium response of climate to a $\mathrm{CO}_{2}$ increase is fully realized. Therefore, we have compared our results with those from the study of Bryan et al. [1982] in which the transient response to a sudden increase of atmospheric $\mathrm{CO}_{2}$ was investigated by use of the coupled ocean-atmosphere model. As pointed out by Bryan et al., the latitudinal distribution of zonally averaged temperature change in the atmosphere and in the oceanic surface layer in response to this $\mathrm{CO}_{2}$ increase becomes qualitatively similar to the distribution of the equilibrium response approximately 25 years after the time of the sudden $\mathrm{CO}_{2}$ increase. (However, the zonally averaged temperature change in the deep ocean for the transient response is very different from that for the equilibrium response.) This result implies that, after approximately 25 years of time integration, the rate of penetration of warm anomaly from the surface layer to the deep ocean of the model is very slow and has a relatively small influence upon the latitudinal distribution of zonally averaged thermal response in the atmospheric and oceanic surface layers. It is of particular interest that, at high latitudes, sea ice and the halocline tend to reduce the heat exchange between the surface atmospheric layer and the subsurface oceanic layers of the model. Therefore, the $\mathrm{CO}_{2}$-induced warming of the surface atmospheric layer at high latitudes turns out to be relatively large even though the temperature of the deep ocean hardly increases. In summary, this study suggests that the distribution of zonally averaged change of surface air temperature in response to a gradual increase of atmospheric $\mathrm{CO}_{2}$ may also resemble the distribution of the equilibrium response, provided that the characteristic time scale of the $\mathrm{CO}_{2}$ increase is longer than 25 years.

Further examination of the results from the transient response experiment reveals that the response of surface air temperature over the ocean significantly lags behind the corresponding response over the continent. A detailed comparison of the geographical distributions of the transient and equilibrium responses is the subject for future research.

It has been suggested that the $\mathrm{CO}_{2}$ concentration in the atmosphere during the Cretaceous epoch was several times larger than the modern concentration [Budyko and Ronov, 1979; Fischer, 1982]. Therefore, the equilibrium response of the coupled ocean-atmosphere model to a $\mathrm{CO}_{2}$ increase, which is discussed in this paper, may have implications for paleoclimatic studies. According to a reyiew article by Savin [1977], the temperature of the deep ocean (as determined from the isotopic analysis of Tertiary benthic foraminifera) has decreased markedly during the last 100 million years. A reduction of almost the same magnitude also occurred in the ocean surface temperature at high latitudes. (See Figure $3 c$ of Savin's paper.) On the other hand, isotopic surface temperature at low latitudes appears to have decreased only slightly during the same period. Emiliani [1954] pointed out that bottom-water temperature anywhere in the world should be indicative of surface water temperature at high latitudes where dense, cold water sinks to form bottom water. The Tertiary change of isotopic temperature described above appears to be consistent with Emiliani's statement. In the present study, the analysis of the equilibrium response of the model ocean to a $\mathrm{CO}_{2}$ increase indicates that the warming of the deep ocean is similar in magnitude to the large warming of the surface layer at high latitudes. In other words, the warming of the deep ocean is significantly larger than the area averaged warming of surface water. The qualitative similarity between the isotopic temperature variation during the Tertiary and the equilibrium response of the model ocean to a $\mathrm{CO}_{2}$ increase suggests that a similar mechanism (i.e., sinking of cold water at high latitudes) is involved in both cases. The process described here is different from an alternative mechanism for the formation of warm deep water (i.e., the sinking of warm saline surface water from the shallow sea in the subtropics as speculated, for example, by Brass et al. [1982]).

It has been noted that the poleward heat transport in the subtropics of the present coupled ocean-atmosphere model is much smaller than the estimates of the actual transport. In the polar region, where the effect of oceanic heat transport is particularly important because of the albedo feedback process, the magnitude of simulated transport, however, is larger than the estimates of the actual transport. Thus, the influence of oceanic heat transport upon the sensitivity of surface air temperature at high latitudes may be overestimated in the present study. It is suggested that this overestimate results from the idealization of geography in the present model.

In addition to the idealization of geography, other simplifying assumptions were made in the construction of the present model, including the use of annually averaged insolation and zonally uniform prescribed cloud cover. It is clear that this study represents only a preliminary attempt to evaluate the influence of oceanic heat transport upon the sensitivity of climate. Further improvement of the coupled oceanatmosphere model is essential for a more reliable assessment of this issue.

Acknowledgments. The authors wish to thank K. Bryan and F Komro for assistance in the modeling and analysis of the ocean component of the coupled ocean-atmosphere model. The constructive comments of $\mathrm{K}$. Bryan, I. Held, and R. Wetherald were very helpful for improving the manuscript. J. Smagorinsky, former Director of the Geophysical Fluid Dynamics Laboratory, gave continual encouragement and support to this project and generously allocated the computer resources needed to complete the time integrations of the models. The authors gratefully acknowledge GFDL staff members $P$. Tunison, W. Ellis, M. Zadworny, and J. Conner for preparation of the figures, M. Jackson for assistance in data analysis, and J. Kennedy for efficient typing of the manuscript.

\section{REFERENCES}

Bourke, W., A multi-level spectral model, 1, Formulation and hemispheric integrations, Mon. Weather Rev., 102, 687-701, 1974

Brass, G. W., J. R. Southam, and W. H. Peterson, Warm Saline bottom water in the ancient ocean, Nature, 296, 620-623, 1982. 
Bryan, K., Climate and the ocean circulation, III, The ocean model, Mon. Weather Rev., 97, 806-827, 1969.

Bryan, K., and L. J. Lewis, A water mass model of the world oceans, J. Geophys. Res., 84, 2503-2517, 1979.

Bryan, K., S. Manabe, and R. C. Pacanowski, A global oceanatmosphere climate model, II, The oceanic circulation, J. Phys. Oceanogr., 5, 30-46, 1975.

Bryan, K., F. G. Komro, S. Manabe, and M. J. Spelman, Transient climate response to increasing atmospheric carbon dioxide, Science, $215,56-58,1982$.

Bryden, H. L., and M. M. Hall, Heat transport by currents across $25^{\circ} \mathrm{N}$ latitude in the Atlantic Ocean, Science, 207, 884-886, 1980

Budyko, M. I., Guide to the Atlas of the Heat Balance of the Earth, Gidrometeoizdat, Moscow, 1963.

Budyko, M. I., The effect of solar radiation variation on the climate of the earth, Tellus, 21, 611-619, 1969.

Budyko, M. I., Climate and Life, Academic, New York, 1974.

Budyko, M. I., and A. B. Ronov, Atmospheric evolution in the Phanerozoic, Geochemistry, 5, 643-653, 1979.

Crutcher, H. L., and J. M. Meserve, Selected level heights, temperatures, and dew points for the northern hemisphere, NAV AIR 50 IC-52, U.S. Naval Weather Serv., Washington, D. C., 1970.

Ellis, J. S., and T. H. Vonder Haar, Zonal average earth radiation budget measurements from satellites for climate studies, Atmos. Sci. Pap. 240, Colorado State Univ., Fort Collins, 1976.

Emiliani, C., Temperature of Pacific bottom waters and polar superficial waters during the Tertiary, Science, 119, 853-855, 1954.

Fischer, A. G., Long-term climatic oscillations recorded in stratigraphy, in Studies in Geophysics, National Academy Press, Washington, D. C., 1982.

Gordon, C. T., and W. Stern, A description of the GFDL global spectral model, Mon. Weather Rev., 110, 625-644, 1982.

Held, I. M., The tropospheric lapse rate and climate sensitivity: Experiments with a two-level atmospheric model, J. Atmos. Sci., 35 , 2083-2098, 1978 .

Held, I. M., and M. J. Suarez, Simple albedo feedback models of ice caps, Tellus, 26, 613-629, 1974.

Held, I. M., D. I. Linder, and M. J. Suarez, Albedo feedback, the meridional structure of the effective heat diffusivity, and climate sensitivity: Results from dynamic and diffusive models, J. Atmos. Sci., 38, 1911-1927, 1981.

Manabe, S., Climate and the ocean circulation, I, The atmospheric circulation and the hydrology of the earth's surface, Mon. Weather Rev., 97, 739-774, 1969.

Manabe, $\mathrm{S}$., $\mathrm{CO}_{2}$ and climatic change, Adv. Geophys., 25, 39-82, 1983.

Manabe, S., and K. Bryan, Climate calculations with a combined ocean-atmosphere model, J. Atmos. Sci., 26, 786-789, 1969.

Manabe, S., and R. J. Stouffer, Sensitivity of a global climate model to an increase of $\mathrm{CO}_{2}$-concentration in the atmosphere, $J$. Geophys. Res., 85, 5529-5554, 1980

Manabe, S., and R. T. Wetherald, Thermal equilibrium of the atmosphere with a given distribution of relative humidity, J. Atmos. Sci., 24, 241-259, 1967.

Manabe, S., and R. T. Wetherald, The effect of doubling the $\mathrm{CO}_{2}$-concentration on the climate of a general circulation model, $J$. Atmos. Sci., 32, 3-15, 1975.

Manabe, S., and R. T. Wetherald, On the distribution of climate change resulting from an increase in $\mathrm{CO}_{2}$-content of the atmosphere, J. Atmos. Sci., 37, 99-118, 1980.

Manabe, S., K. Bryan, and M. J. Spelman, A global oceanatmosphere climate model, I, The atmospheric circulation, J. Phys. Oceanogr., 5, 3-29, 1975.

Oort, A. H., and T. H. Vonder Haar, On the observed annual cycle in the ocean-atmosphere heat balance over the northern hemisphere, J. Phys. Oceanogr., 6, 781-800, 1976.

Robert, A., The integration of a low order spectral form of the primitive equations, J. Meteorol. Soc. Jpn., 44, 237-244, 1966.

Sarmiento, J. L., A simulation of bomb tritium entry into the Atlantic Ocean, J. Phys. Oceanogr., in press, 1983.

Savin, S. M., The history of the earth's surface temperature during the past 100 million years, Ann. Rev. Earth Planet. Sci., 5, 319-355, 1977.

Schneider, S. H., and S. L. Thompson, Atmospheric $\mathrm{CO}_{2}$ and climate: Importance of the transient response, J. Geophys. Res., 86, 31353147,1981 .

Sellers, W. D., Physical Climatology, University of Chicago Press, Chicago, Ill., 1965.

Suarez, M. J., and I. M. Held, The sensitivity of an energy balance climate model to variations in the orbital parameters, J. Geophys. Res., 84, 4825-4836, 1979.

U.S. Navy Hydrographic Office, World atlas of sea surface temperature, Publ. 225, Washington, D. C., 1964.

Wetherald, R. T., and S. Manabe, The effects of changing the solar constant on the climate of a general circulation model, J. Atmos. Sci., 32, 2044-2059, 1975.

Wetherald, R. T., and S. Manabe, Influence of seasonal variation upon the sensitivity of a model climate, J. Geophys. Res., 86, 11941204,1981 .

M. J. Spelman and S. Manabe, Geophysical Fluid Dynamics Laboratory/National Oceanic and Atmosphic Administration, Princeton University, P. O. Box 308, Princeton, NJ 08542.

(Received May 27, 1982; revised May 5, 1983 ; accepted July 26,1983 .) 